\title{
The Impact of The Internet on Global Industry: New Evidence of Internet Measurement
}

\begin{abstract}
August 08th, 2014
Abstract

This paper presents a new way to measure the diffusion of the Internet, using a panel of 10 countries. Different from the previous literature, We use city-level daily databases, downloaded from Cooperative Association for Internet Data Analysis (CAIDA), to construct weekly data across countries. The determinants of Internet cross-traffic traveling are studied using several attributes which offer new opportunities to define network construction and information technology. With the Swiss KOF Globalization Index, this data can be used to reevaluate financial services and business marketing, political interaction and social emergence, and globalization. The major findings are that a significant and positive relationship exists between Internet distance and the different globalization indexes: economic and financial globalization, political globalization, and social globalization. The Internet flows ahead of globalization. The dynamic panel causality analysis demonstrates further empirically the causality of the Internet diffusion on the different indexes of globalization.
\end{abstract}

JEL classification: F10, F15.

Keywords: Internet, Distance, Globalization, Gravity Equation. 


\section{Introduction}

Since the end of the last century, the world has seen many technological innovations, resulting in economic growth and more and more global interactions across countries. There has been a deep and dominant change in financial and social development. The Information Technology (IT) industry, which stimulated great amounts of research concerned with the new definition of globalization. Clark, Wallsten (2000)[7] defined globalization to be the process of creating bridges of connections among agents at multi-continental distances, mediated through a variety of flows including people, information and ideas, capital and goods. When looking at the pattern of the GDP, the growth rate of GDP, or the business cycle, all evidences have shown to this point a comprehensive and continuable influence of the Internet. Most economists agree on the idea that the spike-format increase in the IT industry has triggered this long-term growth since 1990's.

The core question posited by this paper is: Does the Internet contribute to globalization, as measured by the Swiss KOF index? The hypotheses can be simply stated as the following: The Internet is expected to flow ahead of globalization, and its flow is not a concurrent movement with globalization. We expect the relationship between the diffusion of the Internet and globalization to be positive. The influences of the diffusion of the Internet on economic and financial globalization, social globalization, and political globalization are everywhere. The basic evidences are the following: First, the Internet impacts trade of both goods and services. Trade of goods will be affected because Internet technology makes the development of global markets for goods possible, but trade of services will be impacted because new services, which are transmittable via the Internet, can now be traded almost at no cost, irrespective of location. The Internet is therefore likely to have a relatively greater effect on the volume of trade in services. The global market, which concentrates on numerical transactions, gets the greatest jump across 
different markets, such as VoIP phone service, online TV, Telecom, computer goods and services, and financial on-line services in all industries. And due to the tremendous Internet data-dealing systems, the Internet also greatly improves the methods and environment in education institutions and research centers, allowing for availability of continuous twenty-four-hour numerical information. Second, the Internet is likely to decrease the costs of gathering and communicating information. The benefits from increased communication are likely to be larger for more fragmented and less organized groups. Furthermore, researchers $[32,7,31]$ have pointed out that an increase in the availability of information through the Internet's lowering of communication costs implies changes in political outcomes. Finally, the evaluation of institutions and government policies gains new meanings. Besides previous testing possibilities, there are other characteristics, such as accessibility, completeness, efficiency, quality, transparency, and timing. Information comes in may different forms: facts, opinions, stories, interpretations, statistics, etc., and it is created for many purposes. Information exists on many levels of quality or reliability. The time when information is released can be a sign of its credibility. Influenced by the current environment of Internet and informed by the tools of information technology in the last decade, the government strives to prove responsibility and accountability, to maintain transparency and fiscal integrity, to sustain the public trust and to react quickly to the response from industries, while still confronting the rapidly changing and oftentimes threatening financial and economic, political and social environment in which countries work together to serve the world and population. It could be estimated that the faster the Internet develops, the more quickly the information can be transferred, and the more information packets can be sent through different monitors. The Internet allows information to be more quickly transferred, helping the government achieve their goals.

In this paper, we present a new way of measurement for diffusion of the Inter- 
net, and are the first to set up a unique and valuable dataset, using a panel of 10 countries examined from 1998 to 2008. Different from the previous literature, this project uses city-level daily databases from CAIDA(The Cooperative Association for Internet Data Analysis). CAIDA has developed a special tool, Skitter, which actively probes forward IP paths and round trip times (RTTs) from a Skitter host to a specified list of destinations. Thus we can construct the yearly, monthly, and weekly datasets of Internet across countries from Skitter. In investigating the Internet's influence on the cross-country data of globalization, the determinants of Internet cross-traffic traveling consist of several attributes which capture the stability and efficiency of the information travelling and characterize the macroscopic connectivity and performance of the Internet. Unlike World bank datasets, which are the only valuable resources so far for economists to investigate the behavior of the Internet in recent research, the data we gathered from CAIDA characterizes the macroscopic connectivity and performance of the Internet, allowing various topological and geographical representations at multiple levels of aggregation granularity, which provides valuable input for empirically-based modeling of Internet behavior and properties. In other words, CAIDA research provides a new and efficient way to gain insight into the complexity of a large, heterogeneous and dynamic worldwide topology. It's obvious that there are broad ranges of applications to this unique database. In this paper we developed a parallel processing computational statistics method interpreting the Internet trafficing data from 20 cities around the world in a period of 10 years. This allows us to compare the degrees of changes in globalization over a large number of countries before and after the beginning of the century. This paper also contributes to two strands of the international integration literature. First, when combined with the Swiss KOF Globalization Indexes, this new datasets can be used to reevaluate business service, political interaction and social emergence, and globalization. This data is a new form of evidence to support the Swiss KOF Globalization Indexes. Second, under 
this new measurement of the Internet, a significant and positive relationship can be found between Internet distance and the different globalization indexes: financial and economic globalization, political globalization, and social globalization. The Internet flows ahead of globalization. The dynamic panel causality analysis demonstrates further empirically the causality of Internet diffusion on the different indexes of globalization, especially the social globalization. The shock from the annual cycles can be forecasted, and we show that prompt reflection can be traced using the traffic fluctuations.

\section{Literature Review}

With the development of the Internet, network construction, and information technology, we are in a position to talk about "globalization" in a new light. Many previous studies focused on the development of technology, financial activities, and trade volume, based on national-level numerical figures and graphs. When Abramson (2000)[1] suggested Internet globalization indicators, Freund and Weinhold $(2000,2004,2011)[12,13,14]$ stated that the Internet stimulates international trade. Concerned about the direction of causality between web hosts and trade flows, they found that countries with relatively more hosts would trade more, simply because they produce and consume a lot of high-tech products. The data in this paper was taken from the Internet Software Consortium (ISC). It was used to count how many web hosts were attributed to each country by counting top-level host domain names. A top-level domain name is either an ISO country code or one of the generic domains (com/org/net/etc). However, this is certainly not an ideal measure as there is not necessarily any correlation between a host's domain name and where it is actually located. A host could easily be located in the U.S. or any other country, e.g., hosts under the domains EDU/ORG/NET/COM/INT could be located anywhere. Furthermore, although Freund and Weinhold (2004)[13] also 
used the number of Internet users in each country provided in the World Bank to get the ratio on the number of hosts per capita, it is not possible to determine the exact size of the Internet, where hosts are located, or how many users there are. Hofstader (2004) [21] illustrated in his paper "Internet Accessibility: Beyond Disability" that the web has become increasingly pervasive as the Internet grows and technologies spread with many devices previously considered as discrete becoming part of our networked world. This supports the necessity of choosing another measurement for the diffusion of the Internet besides the data provided by World Bank. Greenstein and McDevitt (2012) [17] showed the economic value created in 30 OECD countries correlated with the size of broadband economies. They further proved that the United States conventional government statistics do not capture an unobserved increase in broadband quality since widespread adoption of broadband Internet had occurred without a dramatic decline in prices. Downes and Greenstein (2007) [18] analyzed the geographic spread of commercial Internet Service Providers (ISPs). Universal service in less densely-populated areas was largely believed a function of investment decisions by ISPs with local focus. Greenstein and Mazzeo (2006) [20] examined the role of differentiation among Competitive Local Exchange Carriers (CLECs), and concluded that the policy debate for local telecommunications regulation should account for differentiated behavior. Greenstein and Prince (2006) [19] analyzed the diffusion of the Internet across the United States over the past decade for both households and firms, considering costs and benefits on the demand and supply side, and also discussed the unequal availability and use of the Internet. Their results are based on Internet use, cable connection and home adoption within the national division. Goldfarb and Blum (2006) [16] used gravity equations to measure international electronic commerce. They showed gravity equations hold in the case of digital goods that were consumed over the Internet and had no trading costs, but the effects of distance on electronic commerce mainly focused on the digital 
goods, which depended on taste. Ward (1996) [32] examined how the free flow of information affected political activities. They examined political behavior by relying on imperfect information to explain deviations from welfare maximization in the political process to derive a positive impact of the Internet, but then still needed the empirical data to support their theoretical findings. Portes and Rey (2005) [26] explored a gravity model explained the international gross transaction flows depended on market size in source and destination country as well as trading costs, where both information and the transaction technology played a role on bilateral gross cross-border equity flows. Choi (2010) [6] showed a doubling of Internet usage in a country turned out to lead to a 2 to $4 \%$ increase in service trade. On the other hand, CAIDA has lately posted a number of research papers using the databases set up by the San Diego supercomputing center, partner of Teragrid network, a infrastructure combining leadership class resources at eleven partner sites to create an integrated, persistent computational resource, which are discussing hardware improvements. For instance, Antonelli and Honeyman (2000) [5] demonstrated that with network security threats and vulnerabilities increasing, solutions based on online detection remained attractive, particularly in public institutions. In the public's perception, Firoiu, Boudec, Towsley, and Zhang (2002) [11] pointed out recent advances in theories and models for Internet Quality of Service (QoS). Andres, et al. (2010) [4] found the Internet diffusion process was characterized by a different S-shaped curve in low- or high-income group. Timmis (2012) [30] employed a gravity framework to assess the role of Internet adoption on trade within OECD countries. Lee (2012) [23] supported the network effect of FDI, migration, and the Internet on international trade, and examined differences in the network effect between the manufacturing and service sectors. Sharon et al. (2009) [28] provided the internationalization strategies of Internet start-ups and suggested that the Internet can be employed as a core capability that underpinned the firms' overall international strategy. Terzidis et al. (2013) [29] showed 
the efficiency of alternative electronic communication channels employed by bank management to attract new customers, and the impact of quality of online banking services on customer's trust, overall satisfaction and e-loyalty. Matros et al. (2010) [25] pointed out technical failures influenced service prices which produced volatile prices, and suggested to apply a financial option model to overcome price risk. Gao et al. (2014) [24] studied demand for 3G mobile phone-enabled Internet services and found the pricing-bias problem in the mobile phone usage using consumer-level panel data from a pricing experiment. Pozzi (2013) [27] demonstrated the importance of customers travel costs reduction in the attraction of new business, suggesting that the online channel can help divert business from rival supermarkets. Fahy (2006) [10] found that with accurate information gathered adequate differentiation will insure online profitability equal to that of traditional retailers. Hill (2014) [22] provided an overview of key issues and concepts related to discussions of the Internet, its governance, and the Internet's current governance mechanisms. Finally, for the measurement of globalization, Dreher, Gaston and Martens (2008) [9] defined the three dimensions of the KOF indexes: 1) economic and financial globalization, which is characterized as long-distance flows of goods, capital and services as well as information and perceptions that accompany market exchanges; 2) political globalization, which is characterized by a diffusion of government policies; and 3) social globalization, expressed as the spread of ideas, information, images and people.

The rest of the paper is organized as follows. Section 3 is devoted to an establishment of the Internet measurement and the computing methodology. Detailed data processes and key computational steps are illustrated. The descriptive results are discussed for both topics. The data is then used in Section 4 with the gravity equation to see the relationship between the Internet and global industry, using a panel framework of cross-sectional time series. Section 5 investigates the moment condition specifications. In Section 6, we present a dynamic panel causality anal- 
ysis to demonstrate further empirically that the causality of the Internet diffusion on the different indexes of globalization, especially social globalization. Section 7 concludes the paper.

\section{Data and Computing Methodology}

\subsection{Internet Data}

The data gathered from Skitter characterizes the macroscopic connectivity and performance of the Internet, allows various topological and geographical representations at multiple levels of aggregation granularity, and provides a valuable input for empirical-based modeling of Internet behavior and properties. Skitter sends 52-byte Internet Control Message Protocol (ICMP) echo request packets from an IP address belonging to one of its current monitors, which provides complexities in the current and future Internet. In other words, CAIDA research supplies an insight into the complexity of a large, heterogeneous, and dynamic worldwide topology.

We use data from Skitter to measure the connectivity and the performance of the Internet, i.e., the efficiency of the information traveling through the hops. All data were collected from about ten activated monitors across seven countries for the years 1998-2008. There are seven variables inside our data files, and four of them are the determinants we will discuss in the empirical analysis ${ }^{1}$.

(1) attr_length. This variable represents the attributes of the IP address from San Diego. To check the location of different cities across countries, we can use this variable to represent different cities in our testable experiments.

(2) data_length. This represents the length of the signal sent from the source IP address, say, San Diego, to a specific destination IP address. This variable gives

\footnotetext{
${ }^{1}$ CAIDA provides this dataset franchise through TeraGrid Network and its partners. The sets of data storage run through 10 countries until 2008.
} 
Figure 1: Dynamic Time Plots for Internet Indicators
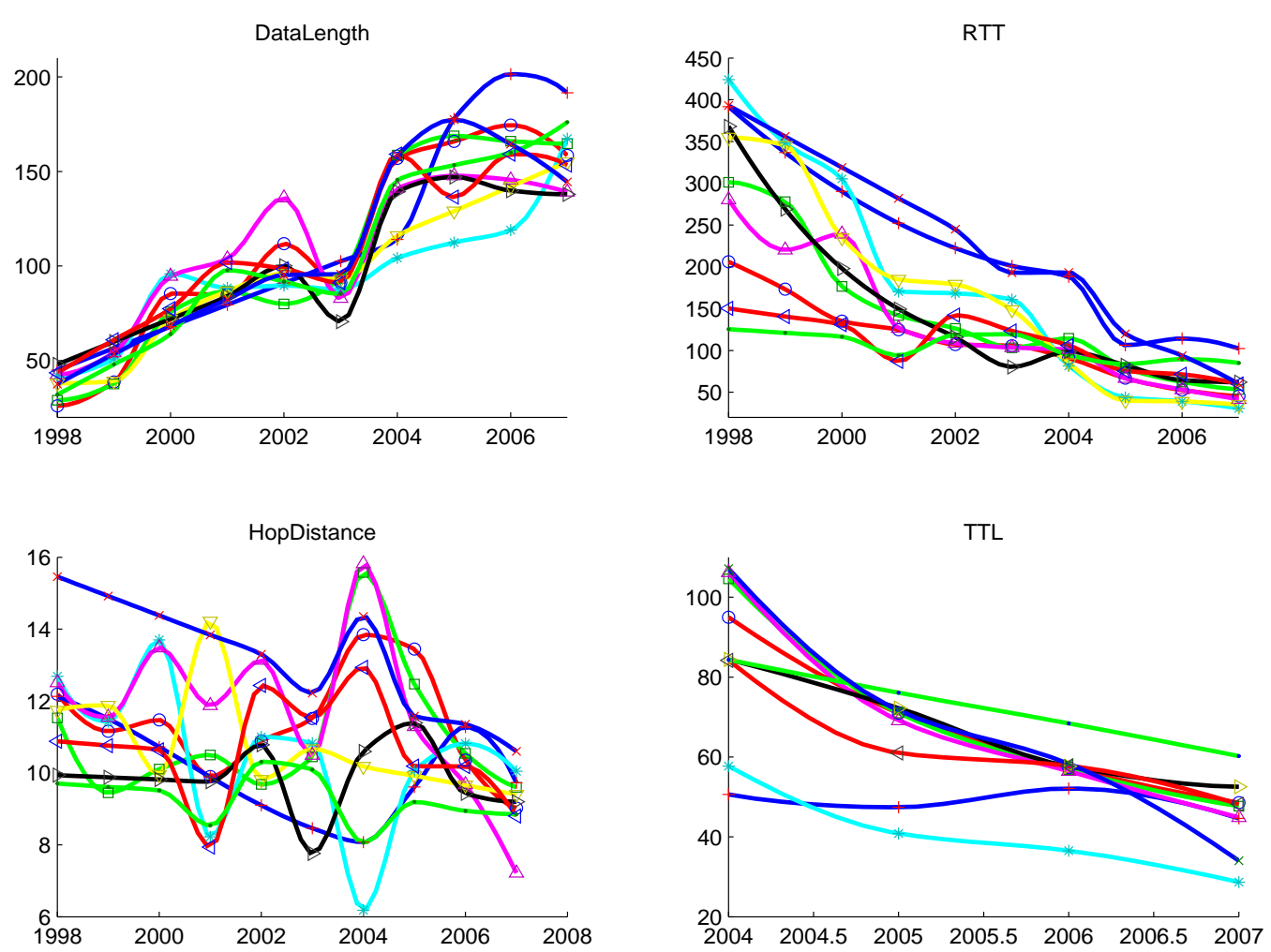

In each subplot, there are ten curves, with each representing the dynamic time plot for different country. The colors and symbols of each curve are denoted as: US(red,o), UK(green, $\square$ ), CN(blue,+), JP(cyan,*), CA(magenta, $\triangle$ ), KR(yellow, $\nabla$ ), FR $($ black,$\triangleright), \mathrm{SE}($ red,$\triangleleft), \mathrm{NL}($ green,$\bullet), \mathrm{NZ}($ blue,$\times)$.

us an opportunity to check the efficiency of the information transformation when we change the size of the length or the ratio of the signal length to the number of the hops.

(3) Src. This gives the exact figure of the source IP address, say, San Diego. This variable should correspond to the variable attr_length. We can use this to check if the signal was sent from the same source monitor.

(4) Dst. This gives the exact figure of the destination IP address. San Diego sent out the invitation to thousands of IP addresses across the world, and any hops echoing the signal fall into the experimental region. In my examination, to date, the number of destination IP addresses are greater than 416,852. The number 
Figure 2: Cross-sectional Dynamic Time Series Plane for Internet Indicators
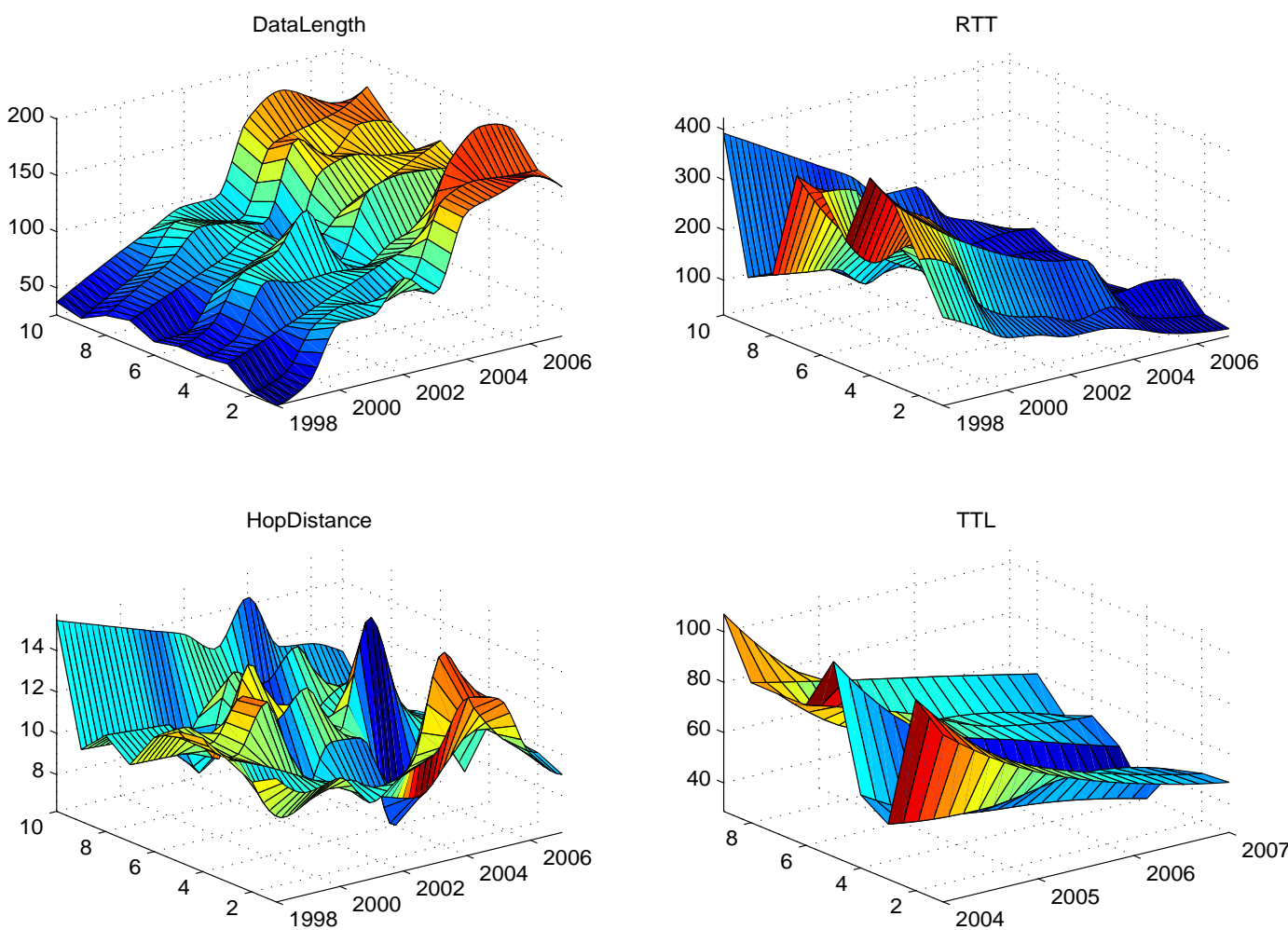

The surface $y=y_{t}^{j}, 1 \leqslant j \leqslant 10,1998 \leqslant t \leqslant 2007$ of the variables of 10 countries, US, UK, CN, JP, CA, KR, FR, SE, NL, NZ, on 10 different dummies from 1998 to 2007.In the subplot for TTL, the time range is from 2004 to 2007, and the country, $\mathrm{KR}$ was excluded.

may have changed after June, 2004, since the data file we compiled seems to have increased dramatically after that period.

(5) RTT. This variable is to count how many round trip times (RTTs) can be attributed to each starting hop in each country for each destination. Skitter has deployed a number of monitors around the world. Each Skitter monitor continuously sends probe packets to destinations in its target list. The number of times each destination is probed per day depends primarily on the total number of destinations in the target list and, to a less extent, on the current global conditions of the network.

(6) HopDistance. This counts how many hops before the signal successfully 
Table 1: The descriptive table of "Data_length" for 10 countries (1998-2007)

\begin{tabular}{lrrrrrrrrrc}
\hline \hline Year & US & UK & CN & JP & CA & KR & FR & SE & NL & NZ \\
\hline 1998 & 26.00 & 29.00 & 45.00 & 42.00 & 42.60 & 38.00 & 48.00 & 43.49 & 32.00 & 37.49 \\
1999 & 38.69 & 37.63 & 56.50 & 50.82 & 54.13 & 39.06 & 60.00 & 60.96 & 48.00 & 53.46 \\
2000 & 85.45 & 75.78 & 68.00 & 95.87 & 94.61 & 71.87 & 72.00 & 77.41 & 64.00 & 68.41 \\
2001 & 84.83 & 86.63 & 79.50 & 88.40 & 103.77 & 86.66 & 84.00 & 101.88 & 97.80 & 82.34 \\
2002 & 111.80 & 79.93 & 91.00 & 89.67 & 136.05 & 96.02 & 100.10 & 98.51 & 91.75 & 95.25 \\
2003 & 91.20 & 93.35 & 102.50 & 87.60 & 82.91 & 92.92 & 70.59 & 91.11 & 85.26 & 95.73 \\
2004 & 156.92 & 158.65 & 114.00 & 104.28 & 141.13 & 116.00 & 139.43 & 159.14 & 145.62 & 158.58 \\
2005 & 165.86 & 168.80 & 177.82 & 112.42 & 147.72 & 129.00 & 147.09 & 136.43 & 153.34 & 177.36 \\
2006 & 174.52 & 165.99 & 201.45 & 118.93 & 145.53 & 142.00 & 139.85 & 159.16 & 160.00 & 164.45 \\
2007 & 158.49 & 164.63 & 191.57 & 167.36 & 139.15 & 155.00 & 137.87 & 153.32 & 176.00 & 144.50 \\
& & & & & & & & & 1.36 & 107.36 \\
Mean & 109.38 & 106.04 & 112.73 & 95.73 & 108.76 & 96.65 & 99.89 & 108.14 & 105.38 & 107.76 \\
Std Dev & 53.30 & 54.25 & 57.50 & 35.09 & 39.22 & 39.95 & 38.01 & 41.92 & 50.47 & 49.86 \\
Skewness & -0.22 & -0.02 & 0.52 & 0.37 & -0.55 & -0.14 & 0.07 & -0.05 & 0.02 & 0.11 \\
Kurtosis & 1.73 & 1.52 & 1.75 & 3.18 & 1.84 & 1.95 & 1.37 & 1.67 & 1.61 & 1.56 \\
\hline
\end{tabular}

Last four rows are statistics for measurable variable "Data_length" across time for each country during 1998-2007.

goes through from the source to many destinations. This also can be used to test the stability and the efficiency of information traveling. We know exactly where the destination IP address is located and the number of hops before reaching the destination, so it's expected that the HopDistance will be large when the number of hops increases and the recursive hops appear, which signals that the information traveling is unstable and inefficient. When the signal sending fails, the HopDistance is zero, so we can also calculate the ratio of failures.

(7) Reply TTL. Skitter data also measures the forward IP paths to record each hop from a source to many destinations by incrementing the so-called "time to live" (TTL) of each IP paths and recording replies from each router (or hop) leading to the destination hosts. This can be used to compare the connectivity of the Internet across times in different countries, compared to only counting how many web hosts are attributed to each country by counting top-level host domain names. Measurement of Reply TTL begins in June 2004, with some testing traces being done in 2003, which accounts for some small numbers in the records, as Table 4 shows. 
Table 2: The descriptive table of "RTT" for 10 countries (1998-2007)

\begin{tabular}{lcccccccccc}
\hline \hline Year & US & UK & CN & JP & CA & KR & FR & SE & NL & NZ \\
\hline 1998 & 206.06 & 301.30 & 391.70 & 424.20 & 280.40 & 355.00 & 368.15 & 150.30 & 125.50 & 393.00 \\
1999 & 173.27 & 277.98 & 336.80 & 348.24 & 220.28 & 345.19 & 269.20 & 140.60 & 121.00 & 356.00 \\
2000 & 135.09 & 176.63 & 290.30 & 305.43 & 239.32 & 234.76 & 198.05 & 130.90 & 116.50 & 319.00 \\
2001 & 124.83 & 141.79 & 252.20 & 170.46 & 126.57 & 184.92 & 149.60 & 86.97 & 94.08 & 282.00 \\
2002 & 107.15 & 126.32 & 222.50 & 168.31 & 108.58 & 179.04 & 115.88 & 142.23 & 118.71 & 245.00 \\
2003 & 105.65 & 103.21 & 201.20 & 160.97 & 103.52 & 148.58 & 80.28 & 123.36 & 119.35 & 193.02 \\
2004 & 90.70 & 114.66 & 188.30 & 81.51 & 100.93 & 85.00 & 98.71 & 106.12 & 94.31 & 193.30 \\
2005 & 66.96 & 78.67 & 106.27 & 43.70 & 66.67 & 40.00 & 82.28 & 75.44 & 83.70 & 119.73 \\
2006 & 52.62 & 62.37 & 114.25 & 39.15 & 53.22 & 39.00 & 64.35 & 71.39 & 89.50 & 93.79 \\
2007 & 45.39 & 53.24 & 102.39 & 30.66 & 41.63 & 35.00 & 62.09 & 59.97 & 85.00 & 60.00 \\
& & & & & & & & & 1.00 \\
Mean & 110.77 & 143.62 & 220.59 & 177.26 & 134.11 & 164.65 & 148.86 & 108.73 & 104.77 & 225.48 \\
Std Dev & 51.42 & 85.49 & 99.11 & 139.28 & 83.19 & 119.77 & 101.33 & 33.22 & 16.76 & 113.24 \\
Skewness & 0.48 & 0.89 & 0.31 & 0.57 & 0.66 & 0.45 & 1.17 & -0.19 & -0.06 & -0.01 \\
Kurtosis & 2.33 & 2.49 & 1.99 & 1.99 & 2.00 & 1.93 & 3.14 & 1.48 & 1.23 & 1.76 \\
\hline
\end{tabular}

Last four rows are statistics for measurable variable "RTT" across time for each country during 1998-2007

\subsection{Computing Methodology}

We are developing a parallel processing computational statistics method for investigating the influence of the Internet under the global comparative environment. The measurements of globalization mainly focus on the financial and economic, social and political dimensions by examining the Internet behavior across the world. This allows us to compare the degree and changes in globalization over a large number of countries before and after the new century period. The method will be used to study the effects of Internet cross-traffic traveling by looking at several attributes, including the round trip times(RTT), which characterizes macroscopic connectivity and performance of the Internet and allows various topological and geographical representations at multiple levels of aggregation granularity. With the development of the Internet, network construction, and information technology, the evaluation of business and services, institutions and government policies has acquired a new sight. We develop the software using $\mathrm{C} / \mathrm{C}++$ and FORTRAN together with an MPI library for the parallel statistical analysis of the Internet 
Table 3: The descriptive table of "HopDistance" for 10 countries (1998-2007)

\begin{tabular}{lccccccccccc}
\hline Year & US & UK & CN & JP & CA & KR & FR & SE & NL & NZ \\
\hline 1998 & 12.19 & 11.53 & 12.13 & 12.69 & 12.51 & 11.74 & 9.94 & 10.88 & 9.71 & 15.46 \\
1999 & 11.16 & 9.45 & 11.51 & 11.43 & 11.55 & 11.88 & 9,88 & 10.76 & 9.61 & 14.92 \\
2000 & 11.47 & 10.11 & 10.72 & 13.70 & 13.48 & 9.95 & 9.82 & 10.64 & 9.52 & 14.38 \\
2001 & 9.90 & 10.50 & 9.89 & 8.23 & 11.88 & 14.22 & 9.76 & 7.94 & 8.54 & 13.84 \\
2002 & 10.89 & 9.68 & 9.10 & 11.00 & 13.14 & 9.81 & 10.78 & 12.44 & 10.31 & 13.30 \\
2003 & 11.52 & 10.45 & 8.46 & 10.83 & 10.50 & 10.67 & 7.76 & 11.54 & 10.10 & 12.22 \\
2004 & 13.85 & 15.58 & 8.08 & 6.18 & 15.82 & 10.18 & 10.60 & 12.94 & 8.06 & 14.35 \\
2005 & 13.45 & 12.47 & 9.61 & 10.07 & 11.29 & 9.92 & 11.39 & 10.19 & 9.19 & 11.58 \\
2006 & 10.36 & 10.54 & 11.28 & 10.82 & 9.68 & 9.66 & 9.43 & 10.18 & 8.95 & 11.35 \\
2007 & 9.02 & 9.60 & 9.73 & 10.05 & 7.22 & 9.40 & 9.20 & 8.80 & 8.85 & 10.60 \\
& & & & & & & & & & \\
Mean & 11.38 & 10.99 & 10.05 & 10.50 & 11.71 & 10.74 & 9.86 & 10.63 & 9.28 & 13.20 \\
Std Dev & 1.50 & 1.86 & 1.34 & 2.12 & 2.33 & 1.48 & 0.99 & 1.51 & 0.70 & 1.66 \\
Skewness & 0.24 & 1.65 & 0.08 & -0.59 & -0.20 & 1.39 & -0.57 & -0.23 & -0.20 & -0.23 \\
Kurtosis & 2.29 & 4.77 & 1.87 & 3.05 & 3.06 & 3.94 & 3.38 & 2.47 & 2.14 & 1.67 \\
\hline
\end{tabular}

Last four rows are statistics for measurable variable "HopDistance" across time for each country during 1998-2007

trafficing data from 10 cities around the world over a period of 10 years. Each set of monthly data from each city is about $64 \mathrm{MB}$ in size and needs to be analyzed initially for seven categories. This seven-category data analysis can be parallelled on multiprocessors. The data is downloaded from its provider (SDSC) and can be located on the system where the software is running. This will allow us to easily access the monthly data and develop statistical methods to analyze the data. We will also develop methods to measure the series correlation between cities in a panel format. A successful development of this computational software can be followed by an MRAC proposal for larger computer resource allocation to allow for more productive data analysis.

Utilizing Skitter Data, we can map dynamic changes in Internet topologies by tracking related performance effects in real-time, using Skitter's RTT data to indicate regions of the infrastructure experiencing abnormal delay, and comparing collapsed Skitter graphs across time. Daily basic Skitter data also uses hop-count distribution to show the number of routers between monitor and it's destinations. 
Table 4: The descriptive table of "TTL" for 10 countries (2004-2007)

\begin{tabular}{lcccccccccc}
\hline \hline Year & US & UK & CN & JP & CA & KR & FR & SE & NL & NZ \\
\hline 2004 & 94.98 & 104.56 & 50.60 & 57.69 & 106.18 & - & 84.42 & 84.18 & 84.32 & 107.14 \\
2005 & 70.99 & 71.03 & 47.41 & 40.85 & 69.11 & - & 72.24 & 60.99 & 76.10 & 71.62 \\
2006 & 57.35 & 56.82 & 52.12 & 36.53 & 56.45 & - & 57.66 & 57.80 & 68.40 & 58.34 \\
2007 & 48.57 & 47.67 & 44.61 & 28.67 & 44.88 & - & 52.54 & 48.17 & 60.20 & 34.00 \\
& & & & & & & & & & \\
Mean & 67.97 & 70.02 & 48.69 & 40.93 & 69.15 & - & 66.72 & 62.78 & 72.25 & 67.77 \\
Std Dev & 20.23 & 24.95 & 3.35 & 12.26 & 26.59 & - & 14.46 & 15.27 & 10.34 & 30.52 \\
Skewness & 0.52 & 0.69 & -0.23 & 0.58 & 0.70 & - & 0.27 & 0.71 & 0.00 & 0.29 \\
Kurtosis & 1.82 & 1.95 & 1.52 & 2.01 & 2.00 & - & 1.49 & 2.09 & 1.66 & 1.90 \\
\hline
\end{tabular}

Last four rows are statistics for measurable variable "TTL" across time for each country during 2004-2007

RTT Distribution shows the frequency of RTT from destinations. RTT Distribution shows the number of IPs between a monitor and its destinations. RTT versus longitude shows the relationship between RTT and longitude of the destination. RTT distribution by continent shows the RTT distribution for each continent.

Using the city-level databases downloaded from the Skitter tools of CAIDA, we collect data from a total of twenty cities scattered around the world. There are ten cities in US: Urbana (IL), Bethesda (MD), College Park (MD), Aberdeen (MD), Moffett Field (CA), Palo Alto (CA), San Jose (CA), San Diego (CA), Eugene (OR), and Washington, DC. The non-US cities are: Cambridge (UK), London (UK), Shenyang (CN), Tokyo (JP), Ottawa (CA), Taejon (KR), Paris (FR), Stockholm (SE), Amsterdam (NL), Auckland (NZ). All the files are the daily records of each monitor from the round-trip tracing. We use the daily files at the end of each month to approximate the monthly behavior, because we have checked and found that, within each month, there is no big fluctuation across different daily files. Compiled files are transferred to ASCII code for reading, and extracted to text files which only contain the details for the seven variables we are interested in. On the platform of PSC, especially the Fed and Pople systems, we use parallel computing to deal with the data mining and numerical analysis. All of the text files for the twenty cities contain continuous behavior of signals, and they 
are in tremendously huge volume. We average the instant measurements of each variable according to a specific number of points to guarantee that each city will have the same amount of derived information for each variable in each month. Furthermore, the monthly data collected is translated into annual data for a 19982008 multivariate dynamic time series. Finally, we use city-level databases to approximate the diffusion of the Internet in different countries. Those cities we investigated are reasonably big enough for approximation, ignoring the scale effect in the measurement.

\subsection{Descriptive Results}

After performing the above computing methodology, we find some patterns in the characteristics of these variables from 1998 to early 2008. For the US, the size of the data packets sent out from the source monitor was 109.38 on average, and the standard deviation was 53.30, with the minimum and maximum size 26 and 174.52. In 2006, the size of the data packets increased to 174.52 , and the standard deviation tripled. The minimum and maximum size of packets tripled too. This trend continues throughout 2007. This means that the capacity for sending information packets has improved and the fluctuation also has more room to carry out.

Examining the number of RTTs in 1998 and 2007, we show the results correspond to our estimation: the Round Trip Time of one information message sent from the source monitor to different destination routers decreases on average. The usage time drops from 206.06 to 45.39 million-seconds. This means that, in 2007, we could send more information per second and, in one second, we could get more information transferred to different countries in the world. This is a better way to prove the stability and the efficiency of information traveling on the current global conditions of the network. 
With respect to the number of hops to a specific destination router, we look at the variable, HopDistance. The results are promising too, since the mean number of hops drops from 12.19 to 9.02 . This means that the traveling paths on the road towards the destination get less, and the time for information sent to the destination decreased as well. We get the positive evidence of stability and the efficiency of the information traveling, which has the same direction for the inference as that of RTT.

Finally, for the forward IP paths to record each hop from a source to many destinations, we look at the variable, Reply TTL. The results are exciting, since the mean of the path number drops from 94.98 to 48.57 . This means that the traveling paths on the road towards the destination get less indeed. This is a better way to compare the connectivity of the Internet across time in different country, compared to only counting how many web hosts are attributed to each country by counting top-level host domain names.

In summary, these are descriptive results for this Internet datasets: Firstly, conducted on a high-speed testbed at the San Diego Supercomputer Center, the Skitter data available on www.caida.org falls into our field to experiment the Internet distance on multiple inputs. Secondly, we have about 20 cities from different countries scattered around the world, and each of them sends out the fixed-length message to about 1 million destination hosts, either located in developed countries or developing countries. Thirdly, in Figure 1-2, data-length of messages, RTT, Hopdistance, and TTL, we can see the overall pattern: for data-length, the messages sent out to multiple destinations get increasing. RTT, Hopdistance, and TTL show downward sloping, indicating that the rounding time for the messages echoing back to resource gets decreasing. This confirms there exists significant improvement in the stability and efficiency of the information traveling, and the connectivity of the Internet across time in different country is enhanced during the time period. This new datasets of Internet measurement are more efficient 
and accurate compared to Freund(2004)[14]. Finally, in the natural experiment framework, we can control all other variables in the gravity equation, then concentrate on four variables for an experiment group before and after June 2004. The outcomes show that the number of destination and the distribution of destination hosts gets huge changes. This results from greater increments in hosts located in developing countries than in developed countries due to substantial upgrades in hardware and franchises.

\subsection{Next Steps}

Skitter data supplies the packets from each monitor across the different destinations, which can capture the effective volumes of information across different cities. This is a very useful measurement for us to test the relationship of the Internet effect on the multiple inputs across different countries. To measure the information volumes of the Internet, CAIDA uses the Skitter data to count how many packets (Pkts) are accumulated to each starting hop by each country by counting Pkts, Pkts/sec, Bytes, and Bits/sec for each destination.

It is shown that, based on Table 1-4, every country gets the same pattern as that of San Diego, as we illustrated above. We can also examine the discrepancy between the countries, due to the difference in the attributes of the Internet measurement. Especially, the financial and economic globalization, social globalization and political globalization have the significant cross-sectional dependence. On the other hand, the change in testing basis for information through different source monitors around June, 2004 and the accordingly persisting influence on different variables can also be studied. 


\subsection{KOF Index of Globalization}

Data on KOF Index of globalization, economic globalization, social globalization, and political globalization are from the KOF website, which was introduced in Dreher (2003)[8], and is updated and described in detail in Dreher, Gaston and Martens (2008)[9]. The overall index covers the financial and economic, social and political dimensions of globalization. Clark, Wallsten (2000)[7] defined globalization to be the process of creating bridges of connections among agents at multi-continental distances, mediated through a variety of flows including people, information and ideas, capital and goods. "Globalization is basically conceptualized as a process that erodes national boundaries, integrates national economies, cultures, technologies and governance and produces complex relations of mutual interdependence."

Dreher, Gaston and Martens (2008)[9] defined the three dimensions of the KOF index: Economic and financial globalization, which was characterized as long distance flows of goods, capital and services as well as information and perceptions that accompanied market exchanges; Political globalization, which was characterized by a diffusion of government policies; And social globalization, expressed as the spread of ideas, information, images and people.

Economic and financial globalization has two dimensions. First, actual financial flows are usually taken to be measures of globalization. Second, the previous literature employs proxies for restrictions on trade and capital. Consequently, two indices are constructed which include individual components suggested as proxies for globalization.

The KOF index of social globalization covers personal contacts, data on information flows and the cultural proximity. It includes international telecom traffic (outgoing traffic in minutes per subscriber) and the degree of tourism (incoming and outgoing). personal contact data is meant to capture measurable interactions 
Figure 3: Dynamic Time Plots for Globalization Indicators
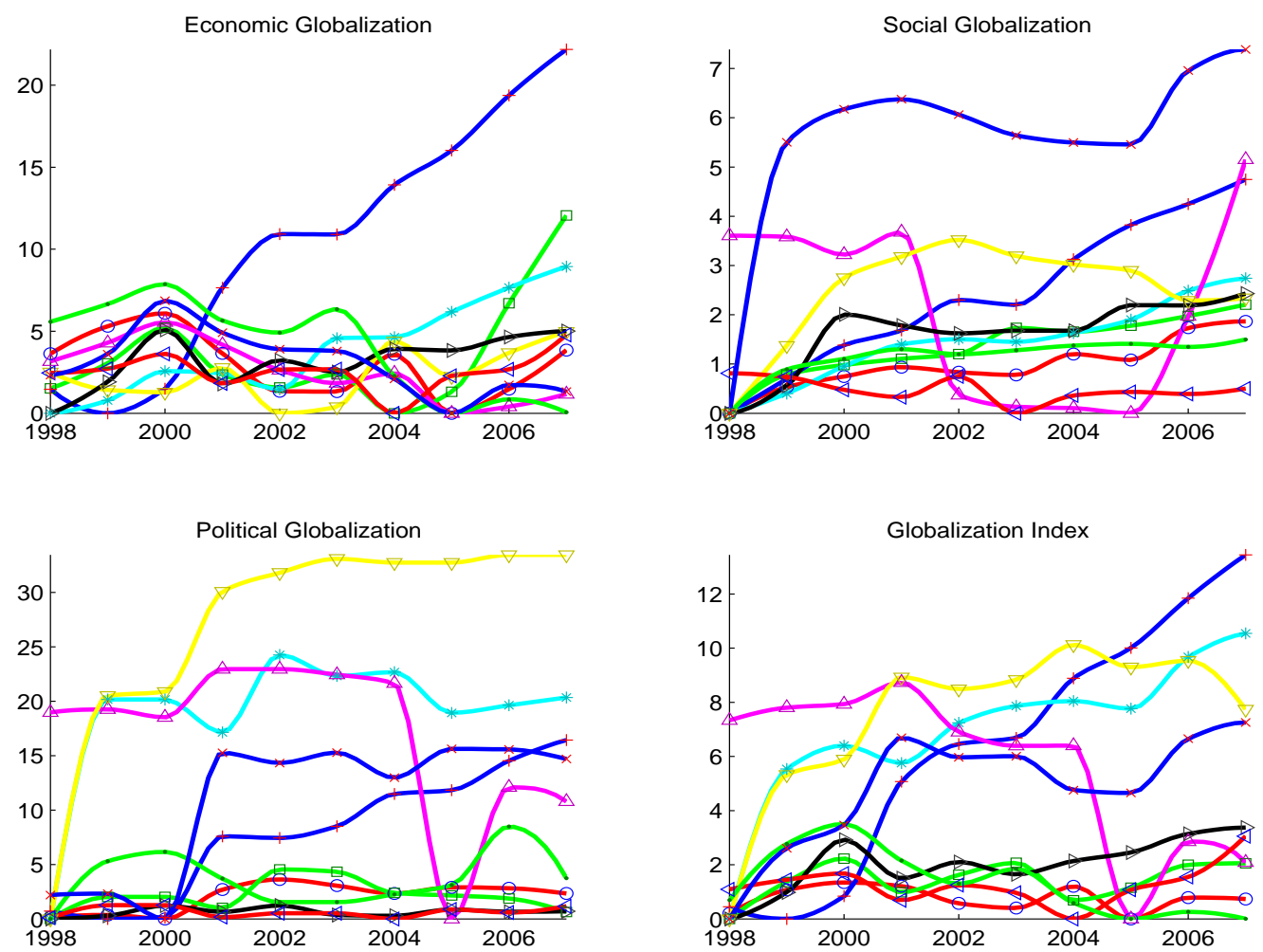

In each subplot, there are ten curves, with each representing the dynamic time plot for different country. The colors and symbols of each curve are denoted as: US(red,o), UK(green, $\square$ ), CN(blue,+), JP(cyan,*), CA(magenta, $\triangle$ ), KR(yellow, $\nabla$ ), FR(black, $\triangleright), \mathrm{SE}($ red, $\triangleleft), \mathrm{NL}($ green, $\bullet), \mathrm{NZ}($ blue, $\times)$. Each index has been deducted by its minimum during the examined time period.

among people from different countries. The sub-index on information flows is meant to measure the potential flow of ideas and images. It includes the number of Internet users, cable television subscribers, number of radios (all per thousands of people), and international newspapers traded (in percentage of GDP).

The most noticeable part inside the measurement for social globalization is that the number of Internet hosts has been excluded from the index as it is no longer provided in the World Telecommunication Indicators Database. This dimension of globalization is captured by the number of Internet users. This also shows that our datasets are good alternatives for these categories. 
Figure 4: Cross-sectional Dynamic Time Series Plane for Globalization Indicators
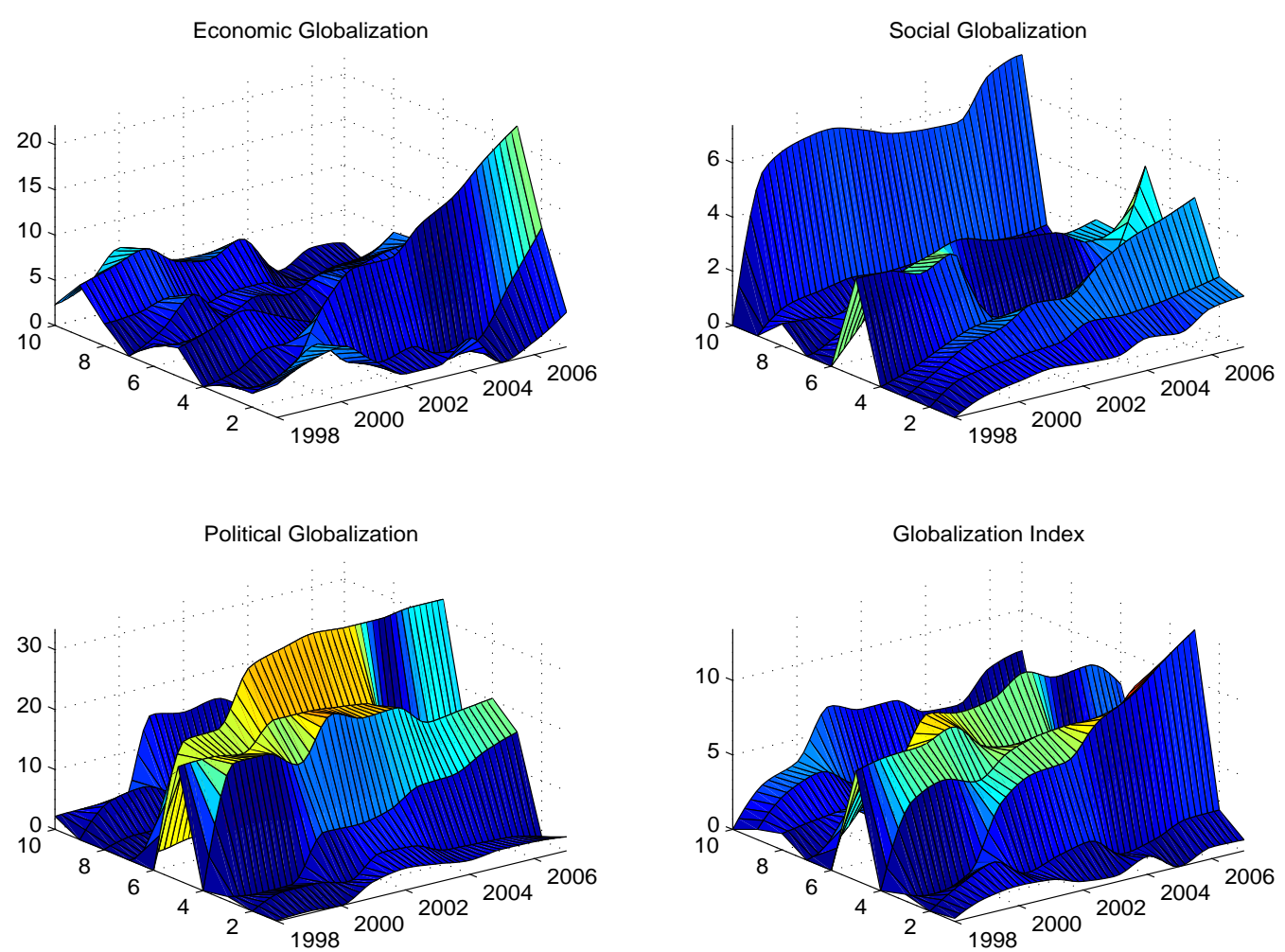

The surface $y=y_{t}^{j}, 1 \leqslant j \leqslant 10,1998 \leqslant t \leqslant 2007$ of the variables of 10 countries, US, UK, CN, JP, CA, KR, FR, SE, NL, NZ, on 10 different dummies from 1998 to 2008.

To proxy the degree of political globalization, the methodology follows A.T. Kearney (2001), employing the number of embassies and high commissions in a country, the number of international organizations to which the country is a member and the number of UN peace missions a country participates in.

The KOF Index of Globalization measures globalization on a scale of 1-100, where the underlying variables enter in percentiles. The impact of extreme data points is thus reduced, and then introduces fewer fluctuations over time. One variable included in the previous version of the index is no longer included, as the original source is not updated: The number of Internet hosts per country. Data is calculated on a yearly basis. In calculating the indexes, all variables are linearly interpolated before applying the weighting procedure. Instead of linear 
Table 5: KOF Index of Globalization and Rankings

\begin{tabular}{|c|c|c|c|c|c|c|c|c|c|c|}
\hline Index & US & UK & $\overline{\mathrm{CN}}$ & $\overline{\mathrm{JP}}$ & $\overline{\mathrm{CA}}$ & KR & FR & $\overline{\mathrm{SE}}$ & NL & $\mathrm{NZ}$ \\
\hline \multicolumn{11}{|c|}{2008} \\
\hline Globalization & 76.76 & 86.67 & 64.56 & 60.91 & 81.21 & 63.56 & 85.38 & 90.02 & 88.40 & 73.40 \\
\hline Ranking & 22 & 7 & 43 & 51 & 15 & 46 & 9 & 3 & 6 & 26 \\
\hline Economic Globalization & 63.15 & 79.24 & 61.54 & 53.84 & 80.83 & 59.36 & 77.42 & 89.51 & 88.04 & 79.68 \\
\hline Ranking & 61 & 27 & 66 & 80 & 23 & 70 & 30 & 6 & 10 & 25 \\
\hline Social Globalization & 76.52 & 87.87 & 49.08 & 52.66 & 86.85 & 52.56 & 84.17 & 87.43 & 89.41 & 72.37 \\
\hline Ranking & 24 & 7 & 64 & 53 & 9 & 55 & 12 & 8 & 5 & 30 \\
\hline Political Globalization & 96.67 & 95.52 & 92.39 & 83.59 & 73.21 & 86.28 & 98.64 & 94.69 & 87.38 & 65.94 \\
\hline Ranking & 2 & 5 & 10 & 29 & 47 & 23 & 1 & 7 & 20 & 54 \\
\hline & & & & & 2007 & & & & & \\
\hline Globalization & 80.83 & 89.29 & 65.26 & 64.22 & 87.49 & 64.82 & 87.71 & 89.89 & 89.15 & 73.46 \\
\hline Ranking & 19 & 4 & 37 & 40 & 7 & 38 & 6 & 3 & 5 & 26 \\
\hline Economic Globalization & 73.00 & 86.12 & 61.21 & 58.36 & 83.09 & 60.12 & 83.95 & 88.52 & 90.18 & 81.21 \\
\hline Ranking & 39 & 10 & 55 & 67 & 18 & 62 & 16 & 8 & 6 & 23 \\
\hline Social Globalization & 77.82 & 87.88 & 50.84 & 54.01 & 86.64 & 54.67 & 84.22 & 88.52 & 89.98 & 73.13 \\
\hline Ranking & 23 & 8 & 62 & 54 & 10 & 53 & 14 & 6 & 4 & 31 \\
\hline Political Globalization & 96.11 & 95.76 & 92.06 & 87.37 & 94.85 & 86.27 & 98.06 & 93.82 & 86.51 & 63.19 \\
\hline Ranking & 2 & 4 & 11 & 18 & 5 & 23 & 1 & 7 & 20 & 56 \\
\hline
\end{tabular}

extrapolation, missing values at the border of the sample are substituted by the latest data available. When data are missing over the entire sample period, the weights are readjusted to correct for this.

Table 5 shows the rankings of these ten countries which fall into our consideration. The most globalized countries to the least globalized are displayed in Table 5. We can see that Sweden and UK are on the top of the globalization ranking. On the bottom of the ranking are Japan and Korea. Countries at the bottom of the ranking consistently score lower across all three dimensions. The degree of globalization in the least globalized countries is about two thirds of those in the most globalized ones. 
Table 6: The descriptive table of "Economic Globalization" for 10 countries (1998-2007)

\begin{tabular}{lrrrrrrrrrr}
\hline \hline Year & US & UK & CN & JP & CA & KR & FR & SE & NL & NZ \\
\hline 1998 & 66.7819 & 79.4536 & 46.9795 & 47.6548 & 83.9940 & 59.6178 & 73.5918 & 89.6787 & 93.6193 & 82.0035 \\
1999 & 68.4567 & 80.9739 & 45.5173 & 48.4322 & 85.1226 & 58.5483 & 75.4992 & 89.9356 & 94.6943 & 83.2821 \\
2000 & 69.2416 & 83.1491 & 47.0125 & 50.2201 & 86.3717 & 58.3992 & 78.6748 & 90.8486 & 95.9040 & 86.5453 \\
2001 & 66.8014 & 80.2941 & 53.1706 & 50.0911 & 85.0120 & 59.8955 & 75.3857 & 89.0441 & 93.6829 & 84.5913 \\
2002 & 64.4913 & 79.5052 & 56.4402 & 49.1081 & 83.4652 & 57.1211 & 76.8134 & 89.8915 & 92.9530 & 83.5833 \\
2003 & 64.4742 & 80.3074 & 56.4167 & 52.2311 & 82.6618 & 57.5078 & 76.1031 & 89.9072 & 94.3882 & 83.4762 \\
2004 & 66.7474 & 77.9362 & 59.4412 & 52.2932 & 83.2681 & 61.5168 & 77.5153 & 87.2245 & 90.3062 & 81.7764 \\
2005 & 63.1536 & 79.2419 & 61.5413 & 53.8384 & 80.8309 & 59.3587 & 77.4222 & 89.5093 & 88.0395 & 79.6808 \\
2006 & 64.6310 & 84.6390 & 64.8970 & 55.3170 & 81.2350 & 60.8100 & 78.2400 & 89.8990 & 88.8900 & 81.4000 \\
2007 & 67.0000 & 90.0000 & 67.7000 & 56.6000 & 82.0000 & 62.1000 & 78.6000 & 92.0000 & 88.1000 & 81.0000 \\
& & & & & & & & & & \\
Mean & 66.1779 & 81.5500 & 55.9116 & 51.5786 & 83.3961 & 59.4875 & 76.7845 & 89.7939 & 92.0577 & 82.7339 \\
Std Dev & 1.9327 & 3.5577 & 7.7382 & 2.9943 & 1.7815 & 1.6492 & 1.6396 & 1.2152 & 2.9433 & 1.9750 \\
Skewness & 0.0111 & 1.4449 & 0.0064 & 0.3429 & 0.1208 & 0.1420 & -0.5647 & -0.3583 & -0.3093 & 0.3899 \\
Kurtosis & 1.9625 & 4.1893 & 1.7683 & 1.9017 & 2.0031 & 1.9281 & 2.3786 & 3.8964 & 1.5239 & 2.6293 \\
\hline
\end{tabular}

Last four rows are statistics for "Economic Globalization" across time for each country during 1998-2007

\section{Model and Results}

\subsection{Model}

As long as we consider how the Internet, globalization, international trade and capital flow, social and political integration interact each other, we can use descriptive statistics to see the behaviors of different variables, carry out the modelling issue, and build up a framework for the following estimation and testing issues.

Anderson (1979)[2, 3] theoretically stated the gravity model based on a "constant" elasticity of substitution preferences and differentiated goods based on the place of the origin of manufacturing. They assumed that the production or the supply is fixed for each good, so the theoretical background begins with the consumers' utility function, which is approximated by a CES utility

$$
\left(\sum_{i} \beta_{i}^{\frac{1-\sigma}{\sigma}} c_{i j}^{-\frac{1-\sigma}{\sigma}}\right)^{-\frac{\sigma}{1-\sigma}}
$$


Table 7: The descriptive table of "Social Globalization" for 10 countries (1998-2007)

\begin{tabular}{lrrrrrrrrrrr}
\hline \hline Year & US & UK & CN & JP & CA & KR & FR & SE & NL \\
\hline 1998 & 75.4335 & 86.0950 & 45.2513 & 50.7606 & 90.4557 & 49.6596 & 81.9701 & 87.8086 & 88.0029 & 66.9104 \\
1999 & 75.9667 & 86.8801 & 45.9490 & 51.1617 & 90.4329 & 51.0321 & 82.5294 & 87.7344 & 88.8952 & 72.4137 \\
2000 & 76.1798 & 87.0751 & 46.6344 & 51.7153 & 90.0697 & 52.4092 & 83.9762 & 87.4717 & 89.1070 & 73.0848 \\
2001 & 76.3699 & 87.2010 & 46.9330 & 52.1600 & 90.5258 & 52.8384 & 83.7530 & 87.3248 & 89.3050 & 73.2863 \\
2002 & 76.2676 & 87.2964 & 47.5520 & 52.2630 & 87.2184 & 53.1813 & 83.5914 & 87.7474 & 89.2012 & 72.9743 \\
2003 & 76.2110 & 87.8282 & 47.4527 & 52.2100 & 86.9801 & 52.8545 & 83.6448 & 86.9968 & 89.2809 & 72.5516 \\
2004 & 76.6370 & 87.7531 & 48.3780 & 52.3901 & 86.9519 & 52.6822 & 83.6453 & 87.3581 & 89.3781 & 72.4080 \\
2005 & 76.5159 & 87.8723 & 49.0760 & 52.6610 & 86.8490 & 52.5571 & 84.1659 & 87.4304 & 89.4143 & 72.3699 \\
2006 & 77.1700 & 88.0700 & 49.5000 & 53.2500 & 88.8200 & 51.9500 & 84.1600 & 87.3880 & 89.3500 & 73.8700 \\
2007 & 77.3000 & 88.3000 & 50.0000 & 53.5000 & 92.0000 & 52.0000 & 84.4000 & 87.5000 & 89.5000 & 74.3000 \\
& & & & & & & & & \\
Mean & 76.4051 & 87.4371 & 47.6726 & 52.2072 & 89.0303 & 52.1164 & 83.5836 & 87.4760 & 89.1435 & 72.4169 \\
Std Dev & 0.5474 & 0.6587 & 1.5544 & 0.8453 & 1.9074 & 1.0569 & 0.7633 & 0.2422 & 0.4359 & 2.0416 \\
Skewness & 0.1106 & -0.6490 & 0.0303 & -0.1734 & 0.0401 & -1.3724 & -1.1520 & -0.3454 & -1.9865 & -2.1484 \\
Kurtosis & 2.6389 & 2.7180 & 1.8882 & 2.3336 & 1.5081 & 3.9401 & 3.1675 & 2.7145 & 5.8918 & 6.6609 \\
\hline
\end{tabular}

Last four rows are statistics for "Social Globalization" across time for each country during 1998-2007

subject to the budget constraint

$$
\sum_{i} p_{i j} c_{i j}=y_{j}
$$

where $\sigma$ is the elasticity of substitution between all goods. $\beta_{i}$ is a positive distribution parameter, $c_{i j}$ is consumption of goods from region $i$ by consumers in region $j, y_{j}$ is the nominal income of consumers in region $j, p_{i j}$ is the price of goods consumed by $j$ consumers from region $i, p_{i j}=p_{i} t_{i j}$, and $t_{i j}$ is the trade cost factor.

The nominal demand derived from maximization condition is

$$
d_{i j}=\left(\frac{\beta_{i} p_{i} t_{i j}}{p_{j}}\right)^{1-\sigma} y_{j}
$$

where

$$
p_{j}=\left[\sum_{i}\left(\beta_{i} p_{i} t_{i j}\right)^{1-\sigma}\right]^{\frac{1}{1-\sigma}}
$$


Table 8: The descriptive table of "Political Globalization" for 10 countries (1998-2007)

\begin{tabular}{lrrrrrrrrrr}
\hline \hline Year & \multicolumn{1}{c}{ US } & UK & CN & JP & CA & KR & FR & SE & NL \\
\hline 1998 & 93.9160 & 93.3660 & 81.2910 & 64.6610 & 92.1870 & 53.5480 & 97.7730 & 93.9340 & 84.2630 & 52.5030 \\
1999 & 94.1290 & 95.3820 & 80.5650 & 84.8210 & 92.4610 & 74.0570 & 98.0610 & 95.0860 & 89.5690 & 52.6270 \\
2000 & 93.7660 & 95.3820 & 80.6890 & 84.8210 & 91.7350 & 74.4200 & 99.0000 & 95.0860 & 90.4190 & 50.3110 \\
2001 & 96.4570 & 94.3770 & 88.1500 & 81.8030 & 96.1660 & 83.6230 & 98.4240 & 93.9970 & 87.9650 & 65.5710 \\
2002 & 97.3960 & 97.9110 & 88.0000 & 88.9120 & 96.1660 & 85.3510 & 99.0000 & 94.3460 & 85.7990 & 64.6340 \\
2003 & 96.8200 & 97.6980 & 89.0750 & 86.9850 & 95.6510 & 86.6390 & 98.1360 & 94.3460 & 85.7990 & 65.5850 \\
2004 & 96.0940 & 95.7450 & 92.0420 & 87.3340 & 94.8500 & 86.2760 & 98.0610 & 93.8310 & 86.5130 & 63.2830 \\
2005 & 96.6700 & 95.5180 & 92.3910 & 83.5900 & 73.2120 & 86.2760 & 98.6370 & 94.6950 & 87.3770 & 65.9360 \\
2006 & 96.5810 & 95.2400 & 95.1000 & 84.2900 & 85.3000 & 87.0000 & 98.4320 & 94.4200 & 92.7500 & 65.8800 \\
2007 & 96.1000 & 94.0000 & 97.0000 & 85.0000 & 84.0000 & 87.0000 & 98.4800 & 95.0000 & 88.0000 & 65.0000 \\
& & & & & & & & & & \\
Mean & 95.7929 & 95.4619 & 88.4303 & 83.2217 & 90.1728 & 80.4190 & 98.4004 & 94.4741 & 87.8454 & 61.1330 \\
Std Dev & 1.3350 & 1.4472 & 5.9637 & 6.8274 & 7.3407 & 10.6824 & 0.4051 & 0.4764 & 2.5142 & 6.5055 \\
Skewness & -0.6315 & 0.4742 & -0.1540 & -2.2357 & -1.3350 & -1.7785 & 0.1785 & 0.0844 & 0.5495 & -0.8599 \\
Kurtosis & 1.7823 & 2.4269 & 1.7377 & 6.8321 & 3.7746 & 5.0493 & 2.0543 & 1.6001 & 2.5777 & 1.8413 \\
\hline
\end{tabular}

Last four rows are statistics for "Political Globalization" across time for each country during 1998-2007

so based on market clearance,

$$
\begin{aligned}
y_{j} & =\sum_{i} x_{i j}=\left(\sum_{i} \frac{\beta_{i} p_{i} t_{i j}}{p_{j}}\right)^{1-\sigma} y_{j} \\
& =\left(\beta_{i} p_{i}\right)^{1-\sigma} \sum_{i}\left(\frac{t_{i j}}{p_{j}}\right)^{1-\sigma} y_{j}, \quad \forall i .
\end{aligned}
$$

the derived gravity equation,

$$
x_{i j}=\frac{y_{i} y_{j}}{\sum_{j} y_{j}} y_{j}\left(\frac{t_{i j}}{p_{i} p_{j}}\right)^{1-\sigma}
$$

which implies that trader barriers reduce size-adjusted trade between large countries more than between small countries, and trader barriers raised sizeadjusted trade within small countries more than within large countries.

Now, the most interesting part is to find the factors of the Internet to affect the trade volume. We applied the following, 
Table 9: The descriptive table of "Globalization Index" for 10 countries (1998-2007)

\begin{tabular}{lrrrrrrrrrrr}
\hline \hline Year & US & UK & CN & JP & CA & KR & FR & SE & NL \\
\hline 1998 & 76.9691 & 85.5237 & 54.9967 & 53.1500 & 88.5481 & 54.2582 & 82.9269 & 90.0372 & 89.0955 & 68.7441 \\
1999 & 77.8356 & 86.8871 & 54.5501 & 58.6867 & 89.0184 & 59.5858 & 83.9070 & 90.3934 & 91.1707 & 71.3529 \\
2000 & 78.1106 & 87.7516 & 55.3875 & 59.5483 & 89.1487 & 60.1523 & 85.8528 & 90.6239 & 91.9062 & 72.2092 \\
2001 & 77.9786 & 86.5093 & 59.6252 & 58.9087 & 89.9513 & 63.1886 & 84.4274 & 89.6370 & 90.5552 & 75.4381 \\
2002 & 77.3383 & 87.1537 & 61.0118 & 60.3899 & 88.1197 & 62.7504 & 85.0294 & 90.1951 & 89.7023 & 74.7153 \\
2003 & 77.1646 & 87.5952 & 61.2371 & 61.0158 & 87.6063 & 63.0911 & 84.5734 & 89.9126 & 90.2539 & 74.7547 \\
2004 & 77.9697 & 86.2115 & 63.4409 & 61.1957 & 87.6129 & 64.3884 & 85.0673 & 88.9472 & 88.9901 & 73.5001 \\
2005 & 76.7644 & 86.6738 & 64.5596 & 60.9135 & 81.2143 & 63.5570 & 85.3791 & 90.0230 & 88.3998 & 73.3960 \\
2006 & 77.5500 & 87.5220 & 66.4000 & 62.8300 & 84.0700 & 63.8000 & 86.0700 & 90.4940 & 88.6600 & 75.4000 \\
2007 & 77.5000 & 87.5800 & 68.0000 & 63.7000 & 83.3000 & 62.0000 & 86.3000 & 92.0000 & 88.4000 & 76.0000 \\
& & & & & & & & & \\
Mean & 77.5181 & 86.9408 & 60.9209 & 60.0339 & 86.8590 & 61.6772 & 84.9533 & 90.2263 & 89.7134 & 73.5510 \\
Std Dev & 0.4590 & 0.7209 & 4.8052 & 2.8902 & 2.9315 & 3.0308 & 1.0377 & 0.7862 & 1.2201 & 2.2496 \\
Skewness & -0.2589 & -0.6416 & -0.0577 & -1.2411 & -0.8708 & -1.5875 & -0.5267 & 0.8007 & 0.5209 & -0.9574 \\
Kurtosis & 1.8087 & 2.4011 & 1.7245 & 4.4158 & 2.3204 & 4.6111 & 2.5221 & 4.1152 & 1.9956 & 3.0117 \\
\hline & & & & & & & & &
\end{tabular}

Last four rows are statistics for "Globalization Index" across time for each country during 1998-2007

$$
t_{i j}=b_{i j} d_{i j} I_{i j}
$$

where $b_{i j}=1$ if $i=j, d_{i j}$ is the geographic distance, $I_{i j}$ is the Internet measurement between region $i$ and $j$. In this paper, we only concentrate on the influence of the Internet on the globalization, especially globalization of the integration from the international service aspects.

Now the fundamental empirical equation is

$\ln x_{i j}=\mathrm{constant}+(1-\sigma) \rho \ln d_{i j}+(1-\sigma) \ln b_{i j}+(1-\sigma) \ln I_{i j}+\ln y_{i}+\ln y_{j}-(1-\sigma) \ln p_{i}-(1-\sigma) \ln p_{j}$,

where $\rho$ is kind of correlation coefficient, then it corresponds to

$$
\widetilde{X}_{i j t}=\beta_{0}+\beta_{1} D_{i j t}+\beta_{2} B_{i j t}+\beta_{3} I_{i j t}+\beta_{4} Y_{i t}+\beta_{5} Y_{j t}+\beta_{6} P_{i t}+\beta_{7} P_{j t}+\beta_{8} K_{i j t}+\widetilde{u}_{i j t} .
$$


where $\tilde{X}_{i j t}$, for $t=1998, \ldots, 2008$, is the international trade, or the international trade either including or excluding non-Internet trading flow, or growth rate of GDP, or the degree of cross-country integrations, which are mainly derived from the international trade and capital flows. It can also be used as the sub-categories for the dependent variables in the above equation. $I_{i j t}$ is the Internet distance; $Y_{i t}$ is the national income of each city or country; $B_{i j t}=1$ if $i=j ; K_{i j t}$ is the other control variables, mainly including generic divergence, and the dummy variable for big-country effect; $P_{i t}$ is the consumer price index in region $i$; $\widetilde{u}_{i j t}$ is the error term of estimation equation. Here, we put all the variables which are not our interests into the constant, which, in term, can be treated as the intercept of the estimation equations. The estimation equation derived here is

$$
\mathbf{X} \equiv f(\mathbf{I}, \mathbf{B}, \mathbf{K}, \mathbf{u})=B K f(\mathbf{I}, \mathbf{u})
$$

where $f: \Re^{i t \times i t} \rightarrow \Re^{i t}$, or, simply,

$$
X_{i j t}=\phi_{0}+\phi_{1} I_{i j t}+\phi_{2} B_{i j t}+\phi_{3} K_{i j t}+u_{i j t}
$$

where $X_{i j t}$ is $\mathrm{KOF}$ index of globalization, financial and economic globalization, social globalization and political globalization. $I_{i j t}$ is the Internet distance, and, in most situation, it is the bandwidth estimation of the cross-traffic travelling distance or other closed-form measurements; $B_{i j t}=1$ if $i=j ; K_{i j t}$ is the measurement stated as above ${ }^{2} ; u_{i j t}$ is the error term of estimation equations.

\subsection{Results}

According to the equation (4.2), we apply the Arellano-Bond methods for panel data to make the estimation for the relationship between the globalization and the

\footnotetext{
${ }^{2}$ The dummy variables, $K_{i j t}$, are summarized into the intercept if we are not in the position to discuss the big-country effects.
} 
diffusion of the Internet. Here we consider the equation (4.2) again with the data described in section $3^{3}$ :

$$
\Delta X_{i t}=\delta_{0}+\delta_{1} \Delta X_{i, t-1}+\delta_{2} \Delta I_{i t}+\delta_{3} \Delta I_{i, t-1}+u_{i t},
$$

where the subscript $i$ and $t$ denote the $i$ th country, $i=1, \ldots, 10$, and the $t$ th year, $t=1, \ldots, 10 . X_{i t}$ is the first-differenced KOF index of globalization, financial and economic globalization, social globalization, or political globalization for country $i$, in year $t$, measured as the variables and weights defined in Dreher (2003)[8]. In this paper, they are the measurements for the bandwidth estimations of the cross-traffic travelling distance, RTT or other closed-form measurements, for instance, Data_Length, HopDistance and TTL, and the lagged terms of $X_{i t}$, $I_{i t}, u_{i t}$. The error terms are assumed as multi-Gaussian and orthogonal to the group of variables for identification.

Specifically, $X_{i, t-1}$ and $I_{i, t-1}$ are treated as exogenous. We assume that $I_{i t}$, $i=1, \ldots, N$, for all $t=1,2, \ldots T$ can be assumed to be exogenous variables, and the additional orthogonality restrictions can be obtained according to strict or weak exogeneity of $X_{i, t-1}$ and $I_{i, t-1}$.

There have evidence supporting the relationship between the globalization and the diffusion of the Internet. We can find the strong dependence within the current and lagged values of related variables, which are significantly shown up in the estimation equation. Here, the coefficient estimates of $X_{i, t-1}$ are positive in all the alternative specifications,except in the last column. Table 10 shows that the coefficients are $0.4353,0.4993,0.5167$ and -0.1642 with independent variable, Data_length, RTT, HopDistance, TTL, respectively, besides the lagged globalization variables. They are significant for $5 \%$ level. The positive and consistent

\footnotetext{
${ }^{3}$ As previous literatures, we firstly run the level-valued estimations based on the above equation (4.2), and test the Auto-Regressive error terms for $\operatorname{AR}(1)$ and $\operatorname{AR}(2)$. Our results show that there exists large significant error correlations. We set up the empirical bases for estimation with the equation (4.3), dropping $j$ subscripts for notation simplicity.
} 
Table 10: The results by using "Globalization Index" as dependent variable

\begin{tabular}{|c|c|c|c|c|}
\hline & Data Length & $\overline{\mathrm{RTT}}$ & HopDistance & TTL \\
\hline Lag-1 globalization Index & $\begin{array}{c}0.4353^{*} \\
(0.0932)\end{array}$ & $\begin{array}{c}0.4993^{*} \\
(0.0997)\end{array}$ & $\begin{array}{c}0.5167^{*} \\
(0.0690)\end{array}$ & $\begin{array}{l}-0.1642 \\
(0.1677)\end{array}$ \\
\hline Data length at time $t$ & $\begin{array}{l}-0.0056 \\
(0.0036)\end{array}$ & - & - & $\begin{array}{l}- \\
-\end{array}$ \\
\hline Lag-1 Data length & $\begin{array}{c}0.0048^{*} \\
(0.0018)\end{array}$ & - & - & - \\
\hline RTT at time $t$ & - & $\begin{array}{c}0.0042^{*} \\
(0.0014)\end{array}$ & - & - \\
\hline Lag-1 RTT & $\begin{array}{l}- \\
-\end{array}$ & $\begin{array}{r}-0.0055^{*} \\
(0.0010)\end{array}$ & $\begin{array}{l}- \\
-\end{array}$ & - \\
\hline HopDistance at time $t$ & $\begin{array}{l}- \\
-\end{array}$ & $\begin{array}{l}- \\
-\end{array}$ & $\begin{array}{r}0.0911 \\
(0.0657)\end{array}$ & - \\
\hline Lag-1 HopDistance & - & $\begin{array}{l}- \\
-\end{array}$ & $\begin{array}{r}-0.1341^{*} \\
(0.0534)\end{array}$ & - \\
\hline TTL at time $t$ & - & - & - & $\begin{array}{l}-0.0283 \\
(0.0197)\end{array}$ \\
\hline Lag-1 TTL & - & $\begin{array}{l}- \\
-\end{array}$ & - & $\begin{array}{l}-0.0188 \\
(0.0155)\end{array}$ \\
\hline $\mathrm{AB} \operatorname{AR}(1)$ & $\begin{array}{l}-1.5300 \\
{[0.1263]}\end{array}$ & $\begin{array}{l}-1.4900 \\
{[0.1356]}\end{array}$ & $\begin{array}{l}-1.7700 \\
{[0.0771]}\end{array}$ & $\begin{array}{r}1.2200 \\
{[0.2242]}\end{array}$ \\
\hline $\mathrm{AB} \operatorname{AR}(2)$ & $\begin{array}{r}1.3300 \\
{[0.1830]}\end{array}$ & $\begin{array}{r}1.1600 \\
{[0.2479]}\end{array}$ & $\begin{array}{r}0.9800 \\
{[0.3275]}\end{array}$ & - \\
\hline
\end{tabular}

Notes: (1) Table is set for the results from the model according to the equation (4.3), applying Arellano-Bond methods for cross-sectional time series to make the estimation for the relationship between the globalization index and the diffusion of the Internet, here, Data_Length, RTT, HopDistance, TTL. The first column contains the independent variables we examined. Intercepts are suppressed. All the entries are the values of estimators correspond to the independent variable in each row. Results here for comparison are GMM estimates. (2) Arellano-Bond test that average autocovariance in residuals of order 1 and 2 is almost 0 failed in $5 \%$ level for all alternative specifications. "*" represents the $5 \%$ significance. The paraphrased figures are the simple standard deviations, and the bracketed ones are the p-values.

coefficient estimates of $X_{i, t-1}$ confirm that the current year's measurable increment for globalization index is adaptive to lagged-one-year's values. Moreover, the insignificant coefficient estimates of $X_{i, t-2}$ reject the lagged-two-year's dependence and are supportive of the model in Table 10. The signs of those estimates are insignificant, which are omitted for reporting. Therefore, in this empirical setup framework, the relationship we examined for series $X_{i, t-1}$ are statistically significant. The Internet measurements $I_{i t}$ are negative in each different estimation process, Data_length and TTL; positive in estimation process, RTT and HopDistance, but the estimators are mostly insignificant. We can find that the current changes in the diffusion of the Internet have no statistically significant relationship to the current globalization index. For estimates of $I_{i, t-1}, 0.48$-point increases in globalization index measurements are associated with one percentage increasing 
Table 11: The results by using "Economic and Financial Globalization" as dependent variable

\begin{tabular}{|c|c|c|c|c|}
\hline & Data Length & RTT & HopDistance & $\overline{\text { TTL }}$ \\
\hline Lag-1 globalization Index & $\begin{array}{c}0.7744^{*} \\
(0.0450)\end{array}$ & $\begin{array}{c}0.7572^{*} \\
(0.0368)\end{array}$ & $\begin{array}{c}0.8007^{*} \\
(0.0960)\end{array}$ & $\begin{array}{c}0.5246^{*} \\
(0.1804)\end{array}$ \\
\hline Data length at time $t$ & $\begin{array}{l}-0.0008 \\
(0.0054)\end{array}$ & $\begin{array}{l}- \\
-\end{array}$ & - & $\begin{array}{l}- \\
-\end{array}$ \\
\hline Lag-1 Data length & $\begin{array}{c}0.0094^{*} \\
(0.0055)\end{array}$ & $\begin{array}{l}- \\
-\end{array}$ & $\begin{array}{l}- \\
-\end{array}$ & $\begin{array}{l}- \\
-\end{array}$ \\
\hline RTT at time $t$ & - & $\begin{array}{r}0.0045 \\
(0.0037)\end{array}$ & - & $\begin{array}{l}- \\
-\end{array}$ \\
\hline Lag-1 RTT & - & $\begin{array}{r}-0.0070^{*} \\
(0.0027)\end{array}$ & - & $\begin{array}{l}- \\
-\end{array}$ \\
\hline HopDistance at time $t$ & - & $\begin{array}{l}- \\
-\end{array}$ & $\begin{array}{r}0.0227 \\
(0.0707)\end{array}$ & $\begin{array}{l}- \\
-\end{array}$ \\
\hline Lag-1 HopDistance & - & $\begin{array}{l}- \\
-\end{array}$ & $\begin{array}{r}-0.2594^{*} \\
(0.0405)\end{array}$ & $\begin{array}{l}- \\
-\end{array}$ \\
\hline TTL at time $t$ & - & - & - & $\begin{array}{l}-0.0048 \\
(0.0199)\end{array}$ \\
\hline Lag-1 TTL & - & $\begin{array}{l}- \\
-\end{array}$ & - & $\begin{array}{r}-0.0618^{*} \\
(0.0190)\end{array}$ \\
\hline $\mathrm{AB} \operatorname{AR}(1)$ & $\begin{array}{l}-2.5700 \\
{[0.0103]}\end{array}$ & $\begin{array}{l}-2.4500 \\
{[0.0143]}\end{array}$ & $\begin{array}{l}-2.5400 \\
{[0.0110]}\end{array}$ & $\begin{array}{r}0.0900 \\
{[0.9291]}\end{array}$ \\
\hline $\mathrm{AB} \operatorname{AR}(2)$ & $\begin{array}{l}-1.0700 \\
{[0.2838]}\end{array}$ & $\begin{array}{l}-1.2400 \\
{[0.2145]}\end{array}$ & $\begin{array}{r}-1.0900 \\
{[0.2741]}\end{array}$ & $\begin{array}{l}- \\
-\end{array}$ \\
\hline
\end{tabular}

Notes: (1) Table is set for the results from the model according to the equation (4.3), applying Arellano-Bond methods for cross-sectional time series to make the estimation for the relationship between the economic globalization and the diffusion of the Internet, here, Data_Length, RTT, HopDistance, TTL. The first column contains the independent variables we examined. Intercepts are suppressed. All the entries are the values of estimators correspond to the independent variable in each row. Results here for comparison are GMM estimates. (2) Arellano-Bond test that average autocovariance in residuals of order 1 and 2 is almost 0 failed in $5 \%$ level for all alternative specifications. "*" represents the $5 \%$ significance. The paraphrased figures are the simple standard deviations, and the bracketed ones are the p-values.

in the lagged-one-period volumes of data packets transferred, which measures the impact on the degree of the globalization across border ${ }^{4}$. Note that in our setup, all the other measurements, RTT, and HopDistance are strongly significant in all model alternatives, 0.55 -point increases in globalization index measurements are associated with one percentage decreasing in the lagged-one-period measures of data-packets-transferred speed time within one round-trip-time. And 0.13-point increases in globalization index measurements are associated with one-point decreasing in the lagged-one-period measures of numbers of hops transferred within one round-trip-time. These results confirm the usefulness of this unique datasets introduced by this paper, and also effectively suggest a new way for measuring the diffusion of the Internet and the impact on the degree of the globalization across

\footnotetext{
${ }^{4}$ Remember that the KOF Index of Globalization measures globalization on a scale of 1-100, where the underlying variables enter in percentiles.
} 
Table 12: The results by using "Social Globalization" as dependent variable

\begin{tabular}{|c|c|c|c|c|}
\hline & Data Length & RTT & HopDistance & TTL \\
\hline Lag-1 globalization Index & $\begin{array}{c}0.4774^{*} \\
(0.0484)\end{array}$ & $\begin{array}{c}0.4921^{*} \\
(0.0555)\end{array}$ & $\begin{array}{c}0.4938^{*} \\
(0.0869)\end{array}$ & $\begin{array}{l}1.4045^{*} \\
(0.1551)\end{array}$ \\
\hline Data length at time $t$ & $\begin{array}{l}-0.0002 \\
(0.0009)\end{array}$ & $\begin{array}{l}- \\
-\end{array}$ & $\begin{array}{l}- \\
-\end{array}$ & - \\
\hline Lag-1 Data length & $\begin{array}{c}0.0027^{*} \\
(0.0011)\end{array}$ & - & $\begin{array}{l}- \\
-\end{array}$ & - \\
\hline RTT at time $t$ & $\begin{array}{l}- \\
-\end{array}$ & $\begin{array}{l}-0.0030 \\
(0.0005)\end{array}$ & $\begin{array}{l}- \\
-\end{array}$ & $\begin{array}{l}- \\
-\end{array}$ \\
\hline Lag-1 RTT & $\begin{array}{l}- \\
-\end{array}$ & $\begin{array}{c}0.0010^{*} \\
(0.0011)\end{array}$ & $\begin{array}{l}- \\
-\end{array}$ & $\begin{array}{l}- \\
-\end{array}$ \\
\hline HopDistance at time $t$ & $\begin{array}{l}- \\
-\end{array}$ & $\begin{array}{l}- \\
-\end{array}$ & $\begin{array}{r}-0.1074^{*} \\
(0.0321)\end{array}$ & $\begin{array}{l}- \\
-\end{array}$ \\
\hline Lag-1 HopDistance & - & - & $\begin{array}{l}-0.0264 \\
(0.0249)\end{array}$ & - \\
\hline TTL at time $t$ & - & - & $\begin{array}{l}- \\
-\end{array}$ & $\begin{array}{c}0.0677^{*} \\
(0.0245)\end{array}$ \\
\hline Lag-1 TTL & - & - & $\begin{array}{l}- \\
-\end{array}$ & $\begin{array}{r}-0.0491^{*} \\
(0.0141)\end{array}$ \\
\hline $\mathrm{AB} \operatorname{AR}(1)$ & $\begin{array}{r}-2.4100 \\
{[0.0158]}\end{array}$ & $\begin{array}{c}-2.0200 \\
{[0.0436]}\end{array}$ & $\begin{array}{l}-1.8600 \\
{[0.0624]}\end{array}$ & $\begin{array}{l}-1.1900 \\
{[0.2325]}\end{array}$ \\
\hline $\mathrm{AB} \operatorname{AR}(2)$ & $\begin{array}{r}2.2400 \\
{[0.0253]}\end{array}$ & $\begin{array}{r}2.0400 \\
{[0.0414]}\end{array}$ & $\begin{array}{r}0.8300 \\
{[0.4040]}\end{array}$ & - \\
\hline
\end{tabular}

Notes: (1) Table is set for the results from the model according to the equation (4.3), applying Arellano-Bond methods for cross-sectional time series to make the estimation for the relationship between the social globalization and the diffusion of the Internet, here, Data_Length, RTT, HopDistance, TTL. The first column contains the independent variables we examined. Intercepts are suppressed. All the entries are the values of estimators correspond to the independent variable in each row. Results here for comparison are GMM estimates. (2) Arellano-Bond test that average autocovariance in residuals of order 1 and 2 is almost 0 failed in $5 \%$ level for all alternative specifications. "*" represents the $5 \%$ significance. The paraphrased figures are the simple standard deviations, and the bracketed ones are the p-values.

border.

On the other hand, in the examination of financial and economic, social, and political globalization, we have similar results supporting the relationship between the globalization and the diffusion of the Internet. Here, the coefficient estimates of $X_{i, t-1}$ are positive in almost all the alternative specifications which are shown in the Table 11-13. The results show that the coefficients are $0.7744,0.7572$, 0.8007 , and $0.5246 ; 0.4774,0.4921,0.4938$, and $1.4045 ; 0.1898,0.0781,0.2428$, and -0.4400 , including independent variable, Data_length, RTT, HopDistance, TTL, respectively, besides the lagged globalization variables. They are significant for $5 \%$ level. The positive and consistent coefficient estimates of $X_{i, t-1}$ confirm that the current year's measurable increment for globalization index is adaptive to lagged-one-year's values ${ }^{5}$. The relationship we examined for series

\footnotetext{
${ }^{5}$ The insignificant coefficient estimates of $X_{i, t-2}$ reject the lagged-two-year's dependence and
} 
Table 13: The results by using "Political Globalization" as dependent variable

\begin{tabular}{|c|c|c|c|c|}
\hline & Data Length & RTT & HopDistance & TTL \\
\hline Lag-1 globalization Index & $\begin{array}{c}0.1898^{*} \\
(0.0681)\end{array}$ & $\begin{array}{r}0.0781 \\
(0.0670)\end{array}$ & $\begin{array}{c}0.2428^{*} \\
(0.0396)\end{array}$ & $\begin{array}{r}-0.4400^{*} \\
(0.0634)\end{array}$ \\
\hline Data length at time $t$ & $\begin{array}{l}-0.0033 \\
(0.0053)\end{array}$ & - & $\begin{array}{l}- \\
-\end{array}$ & - \\
\hline Lag-1 Data length & $\begin{array}{c}0.0160^{*} \\
(0.0018)\end{array}$ & - & $\begin{array}{l}- \\
-\end{array}$ & - \\
\hline RTT at time $t$ & - & $\begin{array}{r}0.0085 \\
(0.0051)\end{array}$ & $\begin{array}{l}- \\
-\end{array}$ & - \\
\hline Lag-1 RTT & - & $\begin{array}{r}-0.0185^{*} \\
(0.0021)\end{array}$ & $\begin{array}{l}- \\
-\end{array}$ & - \\
\hline HopDistance at time $t$ & - & - & $\begin{array}{r}0.0309 \\
(0.1093)\end{array}$ & - \\
\hline Lag-1 HopDistance & - & - & $\begin{array}{l}-0.1890 \\
(0.2683)\end{array}$ & - \\
\hline TTL at time $t$ & $\begin{array}{l}- \\
-\end{array}$ & - & $\begin{array}{l}- \\
-\end{array}$ & $\begin{array}{l}-0.0481 \\
(0.0285)\end{array}$ \\
\hline Lag-1 TTL & $\begin{array}{l}- \\
-\end{array}$ & - & $\begin{array}{l}- \\
-\end{array}$ & $\begin{array}{r}0.0013 \\
(0.0208)\end{array}$ \\
\hline $\mathrm{AB} \operatorname{AR}(1)$ & $\begin{array}{r}-1.3900 \\
{[0.1642]}\end{array}$ & $\begin{array}{l}-1.1600 \\
{[0.1356]}\end{array}$ & $\begin{array}{c}-1.5800 \\
{[0.1137]}\end{array}$ & $\begin{array}{r}0.0600 \\
{[0.9531]}\end{array}$ \\
\hline $\mathrm{AB} \operatorname{AR}(2)$ & $\begin{array}{r}1.2700 \\
{[0.2036]}\end{array}$ & $\begin{array}{r}1.1500 \\
{[0.2521]}\end{array}$ & $\begin{array}{r}1.1600 \\
{[0.2466]}\end{array}$ & - \\
\hline
\end{tabular}

Notes: (1) Table is set for the results from the model according to the equation (4.3), applying Arellano-Bond methods for cross-sectional time series to make the estimation for the relationship between the political globalization and the diffusion of the Internet, here, Data_Length, RTT, HopDistance, TTL. The first column contains the independent variables we examined. Intercepts are suppressed. All the entries are the values of estimators correspond to the independent variable in each row. Results here for comparison are GMM estimates. (2) Arellano-Bond test that average autocovariance in residuals of order 1 and 2 is almost 0 failed in $5 \%$ level for all alternative specifications. "*" represents the $5 \%$ significance. The paraphrased figures are the simple standard deviations, and the bracketed ones are the p-values.

$X_{i, t-1}$ are also statistically significant for each sub-category measures for globalization. The Internet measurements $I_{i t}$ are negative in each different estimation process, Data_length and TTL; positive in estimation process, RTT and HopDistance, but the estimators are all insignificant, by using financial and economic globalization and political globalization as dependent variables. We can find that the current changes in the diffusion of the Internet have no statistically significant relationship to the current financial and economic globalization and political globalization. But for the social globalization, we find statistically significant relationship between the current social globalization and the current changes in the diffusion of the Internet, using RTT and Hopdistance.

For estimates of $I_{i, t}, 0.30$-point increase in social globalization measurements are supportive of the model in Table 11-13. The signs of those estimates are insignificant, which is omitted for reporting. 
are associated with one percentage decreasing in the lagged-one-period measures of data-packets-transferred speed within one round-trip-time, and 0.11-point increase in social globalization measurements are associated with one-point decreasing in the lagged-one-period measures of numbers of hops transferred within one roundtrip-time. These results interestingly point out that the Internet measurements of this unique data sets introduced by this paper effectively suggest a new way for measuring the diffusion of the Internet, which traces the social interactions between multinational continents.

For estimates of $I_{i, t-1}, 0.94$-point increase in financial and economic globalization, and 1.60-point increase in political globalization measurements are associated with one percentage increasing in the lagged-one-period volumes of data packets transferred, which measures the impact on the degree of the globalization across border. For all the other measurements, RTT, and HopDistance, 0.70-point increase in financial and economic globalization, and 0.19-point increase in political globalization measurements are associated with one percentage decreasing in the lagged-one-period measures of data-packets-transferred speed within one roundtrip-time, and 0.26-point increase in financial and economic globalization, and 0.19-point increase in political globalization measurements are associated with one-point decreasing in the lagged-one-period measures of numbers of hops transferred within one round-trip-time. On the contrary, there are of no significance between the current social globalization and the one-period-lagged measurements for the Internet diffusion.

Based on our results, aggregate cross-sectional time series data shows consistent evidence to support for the dependence between the globalization and oneperiod-lagged Internet diffusion. Arellano-Bond tests that average autocovariance in residuals of order 2 is 0 fail in $5 \%$ level for almost all columns, so putting the lagged Internet measurement series into the explainary sets has been statistically approved. The probability of not rejecting the hypothesis of average autocovari- 
ance in residuals of order 2 is 0 range from 0.08 to 0.33 , which is explicitly showing that the higher-order residuals yield no autocorrelation. The impact of the Internet diffusion on globalization is supported in the empirical results by using this unique data set. In Table 10, it should be noticed that the $I_{i, t-1}$, the laggedone-period Internet diffusion, puts strong positive impact on the current trend of globalization, where the coefficient $\delta_{3}$ is the percentage increment in the above theoretical model, which support the impact from the Internet diffusion on the global integration, not the inverse way. we may argue that it will become reasonable if we use the Internet diffusion rate to calculate the network incentive, not the proxy variable which results from the global geography, local distance and neighboring price for services.

\section{Moment Condition Specification}

After addressing the detailed results of model specification, we discuss here the potential endogeneity problem inferring from that gravity equations illustrated above. We assume that there is no third factor that causes the Internet traffic to increase and later causes the globalization measure to increase. In the absence of such a cause, then we state that one causes the other. Actually, we firstly run the level-valued estimations based on the above equation (4.2), and test the Auto-Regressive error terms for $\mathrm{AR}(1)$ and $\mathrm{AR}(2)$. Our results show that there exists large significant error correlations. Arellano-Bond tests show that average autocovariance in residuals of order 2 is statistically 0 . The probability of not rejecting the hypothesis of average autocovariance in residuals of order 2 is 0 range from 0.08 to 0.33 , which is explicitly showing that the higher-order residuals yield no autocorrelation.

When the problem of omitted variables comes out, it is reasonable to lead to bias which are caused by the endogeneity issues. If the assumption of putting 
Internet measurement into structural equation and even into instrument variables set is valid, and the lag-one-period diffusion of the Internet is really capturing the positive effects on degree of globalization, we should find the evidence to support this economic effect. Moreover, we empirically found that the significant impact on the different indexes of globalization for all the alternative measurements of the Internet.

The reason is that the lag-one-period diffusion of the Internet cross-border may be correlated to the current degree of globalization. Actually, there exists a strong correlation between these two variables. Dragging current degree of globalization inside the structural equation can avoid the omitted variable problem, and make the Internet measurements to be valid instruments to estimate the bilateral international digital trade in next statistical period. The overall IV identification testing can be used to see the size of the IV relevance in the first-stage, and prepare to carry out the empirical estimation process.

Let's reinvestigate the descriptive results of this data set, which are illustrated before in section 3.1. The measurements for each country in period 1998-2007 are listed in Table 1-4, where the last four rows are statistics of annual data covering the time period. The identification issue is one of the basic step for estimation, if we want to use the data to capture the correlations between the variables interested. In our empirical model above, we assume that the error terms which cannot be observed are multi-Gaussian distribution conditional on the Internet variables. The linear correlations in the regressions count heavily on the multi-dimensional distribution of errors conditional on the explanatory variables, where the regressions can begin towards the estimations and inferences. The (weak) orthogonal conditions between the error terms and the explanatory groups are the bases for consistency and efficiency issues, which is, of course, the reason for the potential bias in the maximum likelihood estimation process. We can anticipate that the relationship between the Internet measurement and the globalization can be treated 
as multivariate Gaussian. Furthermore, the correlation between Globalization and the diffusion of the Internet may even be useful for picking the diffusion of the Internet as the potential available IV sets for estimation in structural equations, such as traditional gravity equations and probit-logit models.

\section{Dynamic Panel Causality and Sensitivity Anal- ysis}

To study the direction of dependency between two random variables, a very powerful tool is the Granger causality test, but this method is checking the lagged terms of pairwise multivariate time series in vector autoregression. In the sequel, we want to turn the attention to the dynamic panel causality through quasisensitivity analysis of the variables $\left\{X_{t}^{i}\right\}$ and $\left\{I_{t}^{j}\right\}$. Arellano-Bond methods for cross-sectional time series make the estimation for the causality of diffusion of the Internet, here, Data_Length, RTT, HopDistance, TTL, on the globalization index, which allows us to separate the effect of the dependence from the inverse effects of the independent variables.

According to the equation (4.3), we apply the Arellano-Bond methods for panel data to make the estimation for the relationship between the globalization and the diffusion of the Internet. consider the equation (4.2) again inversely, with the data described in section 3 , dropping $j$ subscripts for notation simplicity:

$$
\Delta I_{i t}=\delta_{0}+\delta_{1} \Delta I_{i, t-1}+\delta_{2} \Delta X_{i t}+\delta_{3} \Delta X_{i, t-1}+v_{i t}
$$

where, as previous described, the subscript $i$ and $t$ denote the $i$ th country, $i=1, \ldots, 10$, and the $t$ th year, $t=1, \ldots, 10 . X_{i t}$ is the first-differenced KOF index of globalization, economic globalization, social globalization, or political globalization for country $i$, in year $t$, measured as the variables and weights defined in 
Dreher (2003) [8]. In this paper, they are the measurements for the bandwidth estimations of the cross-traffic travelling distance, RTT or other closed-form measurements, for instance, Data_Length, HopDistance, and TTL, and the lagged terms of $X_{i t}, I_{i t} \cdot v_{i t}$, the error term, is assumed as multi-Gaussian and orthogonal to the group of variables for identification.

Table 14: The results by using "Globalization Index" as independent variable

\begin{tabular}{lrrrr}
\hline \hline & Data Length & RTT & HopDistance & TTL \\
\hline Lag-1 Data length & $0.7940^{*}$ & - & - & - \\
& $(0.0539)$ & - & - & - \\
Lag-1 RTT & - & $0.7994^{*}$ & - & - \\
& - & $(0.0181)$ & - & - \\
Lag-1 HopDistance & - & - & 0.2098 & - \\
& - & - & $(0.1292)$ & - \\
Lag-1 TTL & - & - & - & $0.6369^{*}$ \\
& - & - & - & $(0.0800)$ \\
Globalization Index at time $t$ & -3.8411 & 2.1602 & 0.0738 & 0.7254 \\
& $(2.9630)$ & $(2.7536)$ & $(0.1410)$ & $(0.9308)$ \\
Lag-1 Globalization Index & $3.9387^{*}$ & $-3.6992^{*}$ & $-0.1659^{*}$ & $-1.5219^{*}$ \\
& $(1.0883)$ & $(0.9331)$ & $(0.0756)$ & $(0.4092)$ \\
\hline \multirow{2}{*}{ AB AR(1) } & -2.2200 & -2.4200 & -2.1400 & -1.9300 \\
& {$[0.0263]$} & {$[0.0156]$} & {$[0.0156]$} & {$[0.0539]$} \\
AB AR(2) & 1.3200 & -0.1500 & 0.8800 & - \\
& {$[0.1877]$} & {$[0.8835]$} & {$[0.3799]$} & - \\
\hline
\end{tabular}

Notes: (1) Table is set for the results from the model according to the equation (6.1), applying Arellano-Bond methods for cross-sectional time series make the estimation for the causality of diffusion of the Internet, here, Data_Length, RTT, HopDistance, TTL, on the globalization index. The first column contains the independent variables we examined. Intercepts are suppressed. All the entries are the values of estimators correspond to the independent variable in each row. Results here for comparison are GMM estimates. (2) Arellano-Bond test that average autocovariance in residuals of order 1 is almost 0 not failed in $5 \%$ level for all alternative specifications. Arellano-Bond test that average autocovariance in residuals of order 2 is almost 0 failed in $5 \%$ level for all alternative specifications. "*" represents the $5 \%$ significance. The paraphrased figures are the simple standard deviations, and the bracketed ones are the $\mathrm{p}$-values.

We have evidence supporting the causality of lag-one-period diffusion of the Internet on the current degree of globalization. There exists weak lag-one-period causality from the Internet on the current values of related variables, but ArellanoBond test that average autocovariance in residuals of order 1 is almost 0 does not fail in 5\% level for all alternative specifications. Here, the coefficient estimates of $X_{i, t-1}$ are negative in most of the alternative specifications, except in the first column. Table 14 shows that the coefficients are $3.9387,-3.6992,-0.1659$, and -1.5219, including dependent variable, Data_length, RTT, HopDistance, TTL, respectively, besides the lagged values. They are significant for $5 \%$ level. The neg- 
Table 15: The results by using "Economic and Financial Globalization" as independent variable

\begin{tabular}{|c|c|c|c|c|}
\hline & Data Length & RTT & HopDistance & TTL \\
\hline Lag-1 Data length & $\begin{array}{c}0.8242^{*} \\
(0.0309)\end{array}$ & - & - & - \\
\hline Lag-1 RTT & - & $\begin{array}{c}0.8360^{*} \\
(0.0179)\end{array}$ & - & - \\
\hline Lag-1 HopDistance & - & - & $\begin{array}{r}0.2136 \\
(0.2203)\end{array}$ & - \\
\hline Lag-1 TTL & - & - & - & $\begin{array}{c}0.7562^{*} \\
(0.1239)\end{array}$ \\
\hline Economic Globalization at time $t$ & $\begin{array}{l}-0.5106 \\
(1.5975)\end{array}$ & $\begin{array}{r}0.0573 \\
(0.9809)\end{array}$ & $\begin{array}{l}-0.0110 \\
(0.0656)\end{array}$ & $\begin{array}{r}1.8944 \\
(1.2686)\end{array}$ \\
\hline Lag-1 Economic Globalization & $\begin{array}{r}1.9648 \\
(0.9863)\end{array}$ & $\begin{array}{l}-1.2417 \\
(1.0820)\end{array}$ & $\begin{array}{r}-0.0953^{*} \\
(0.0310)\end{array}$ & $\begin{array}{l}-1.7241 \\
(1.2371)\end{array}$ \\
\hline $\operatorname{AB} \operatorname{AR}(1)$ & $\begin{array}{r}-2.2400 \\
{[0.0254]}\end{array}$ & $\begin{array}{r}-2.4500 \\
{[0.0142]}\end{array}$ & $\begin{array}{c}-2.2400 \\
{[0.0250]}\end{array}$ & $\begin{array}{r}-2.0100 \\
{[0.0443]}\end{array}$ \\
\hline $\mathrm{AB} \operatorname{AR}(2)$ & $\begin{array}{r}1.2200 \\
{[0.2219]}\end{array}$ & $\begin{array}{c}-0.3900 \\
{[0.6951]}\end{array}$ & $\begin{array}{r}0.9300 \\
{[0.3542]}\end{array}$ & - \\
\hline
\end{tabular}

\footnotetext{
Notes: (1) Table is set for the results from the model according to the equation (6.1), applying Arellano-Bond methods for cross-sectional time series make the estimation for the causality of diffusion of the Internet, here, Data_Length, RTT, HopDistance, TTL, on the economic globalization. The first column contains the independent variables we examined. Intercepts are suppressed. All the entries are the values of estimators correspond to the independent variable in each row. Results here for 1 is residuals of order 2 is almost 0 failed in $5 \%$ level for all alternative specifications. "*" represents the 5\% significance. The residuals of order 2 is almost 0 failed in $5 \%$ level for all alternative specifications. "*" represents
paraphrased figures are the simple standard deviations, and the bracketed ones are the p-values.
}

ative and consistent coefficient estimates of $X_{i, t-1}$ disappoint us that the current year's measurable increment for globalization index is adaptive to lagged-oneyear's values of the Internet measurement. But the story is not ended yet.

On the other hand, in the examination of economic and financial, social, and political globalization, we have exciting results supporting the lag-one-period diffusion of the Internet's causality on the current globalization. Here, the coefficient estimates of $X_{i, t-1}$ are insignificant in almost all the alternative specifications in the Table 15-17. The results show that the coefficients are 1.9648, $-1.2417,-0.0953$ and $-1.7241 ; 4.0476,0.7365,0.2319$ and $-9.4593 ; 0.9138,-0.9237,-0.0770$ and -0.5621, including dependent variable, Data_length, RTT, HopDistance, TTL, respectively, besides the lagged values of variables. They are strongly insignificant for $5 \%$ level, even for $10 \%$ level for most alternative specifications. The consistently insignificant coefficient estimates of $X_{i, t-1}$ confirm that the current year's measurable increment for sub-category globalization index is adaptive to lagged- 
Table 16: The results by using "Social Globalization" as independent variable

\begin{tabular}{|c|c|c|c|c|}
\hline & Data Length & RTT & HopDistance & TTL \\
\hline Lag-1 Data length & $\begin{array}{c}0.8187^{*} \\
(0.0282)\end{array}$ & $\begin{array}{l}- \\
-\end{array}$ & $\begin{array}{l}- \\
-\end{array}$ & $\begin{array}{l}- \\
-\end{array}$ \\
\hline Lag-1 RTT & $\begin{array}{l}- \\
-\end{array}$ & $\begin{array}{c}0.8066^{*} \\
(0.0246)\end{array}$ & $\begin{array}{l}- \\
-\end{array}$ & $\begin{array}{l}- \\
-\end{array}$ \\
\hline Lag-1 HopDistance & $\begin{array}{l}- \\
-\end{array}$ & $\begin{array}{l}- \\
-\end{array}$ & $\begin{array}{l}-0.0088 \\
(0.2628)\end{array}$ & - \\
\hline Lag-1 TTL & $\begin{array}{l}- \\
-\end{array}$ & $\begin{array}{l}- \\
-\end{array}$ & $\begin{array}{l}- \\
-\end{array}$ & $\begin{array}{c}0.5779^{*} \\
(0.0415)\end{array}$ \\
\hline Social Globalization at time $t$ & $\begin{array}{l}-1.0614 \\
(5.9552)\end{array}$ & $\begin{array}{r}-6.9102^{*} \\
(2.3225)\end{array}$ & $\begin{array}{r}-1.3263^{*} \\
(0.4558)\end{array}$ & $\begin{array}{c}4.3869^{*} \\
(1.1426)\end{array}$ \\
\hline Lag-1 Social Globalization & $\begin{array}{r}4.0476 \\
(3.2280)\end{array}$ & $\begin{array}{r}0.7365 \\
(1.6095)\end{array}$ & $\begin{array}{r}0.2319 \\
(0.1132)\end{array}$ & $\begin{array}{r}-9.4593^{*} \\
(2.0048)\end{array}$ \\
\hline $\operatorname{AB} \operatorname{AR}(1)$ & $\begin{array}{l}-2.3100 \\
{[0.0211]}\end{array}$ & $\begin{array}{c}-2.5200 \\
{[0.0156]}\end{array}$ & $\begin{array}{l}-1.5100 \\
{[0.1300]}\end{array}$ & $\begin{array}{r}-1.5200 \\
{[0.1276]}\end{array}$ \\
\hline $\operatorname{AB} \operatorname{AR}(2)$ & $\begin{array}{r}0.9500 \\
{[0.3444]}\end{array}$ & $\begin{array}{c}-0.4800 \\
{[0.6302]}\end{array}$ & $\begin{array}{l}-0.4200 \\
{[0.6728]}\end{array}$ & - \\
\hline
\end{tabular}

Notes: (1) Table is set for the results from the model according to the equation (6.1), applying Arellano-Bond methods for cross-sectional time series make the estimation for the causality of diffusion of the Internet, here, Data_Length, RTT, HopDistance, TTL, on the social globalization. The first column contains the independent variables we examined. Intercepts are suppressed. All the entries are the values of estimators correspond to the independent variable in each row. Results here for comparison are GMM estimates. (2) Arellano-Bond test that average autocovariance in residuals of order 1 is almost 0 not failed in $5 \%$ level for all alternative specifications. Arellano-Bond test that average autocovariance in residuals of order 2 is almost 0 failed in $5 \%$ level for all alternative specifications. "*" represents the $5 \%$ significance. The paraphrased figures are the simple standard deviations, and the bracketed ones are the $\mathrm{p}-$-values.

one-year's values. Here, the insignificant coefficient estimates of $X_{i, t-1}$ reject the lagged-one-year's dependence and are supportive of the model in Table 11-13. The signs of those estimates are insignificant too, so the relationships we examined for series $I_{i, t-1}$ are statistically significant for each sub-category measures for globalization. The Internet measurement, $I_{i t}$ is negative in each different estimation process, Data_length and TTL, RTT and HopDistance, and the estimators of $X_{i, t-1}$ are all insignificant, by using economic and financial globalization, social globalization and political globalization as independent variables. We can find that the lag-one-period changes in the diffusion of the Internet have statistically significant relationship to the current economic and financial globalization, political globalization, and social globalization. Especially for social globalization, we find statistically significant relationship between the current social globalization and the current changes in the diffusion of the Internet. These results further confirm that the Internet measurements of this unique datasets introduced by this 
Table 17: The results by using "Political Globalization" as independent variable

\begin{tabular}{|c|c|c|c|c|}
\hline & Data Length & RTT & HopDistance & TTL \\
\hline Lag-1 Data length & $\begin{array}{c}0.8043^{*} \\
(0.0656)\end{array}$ & - & $\begin{array}{l}- \\
-\end{array}$ & - \\
\hline Lag-1 RTT & $\begin{array}{l}- \\
-\end{array}$ & $\begin{array}{c}0.8261^{*} \\
(0.0143)\end{array}$ & $\begin{array}{l}- \\
-\end{array}$ & $\begin{array}{l}- \\
-\end{array}$ \\
\hline Lag-1 HopDistance & - & - & $\begin{array}{c}0.3529^{*} \\
(0.1216)\end{array}$ & - \\
\hline Lag-1 TTL & - & $\begin{array}{l}- \\
-\end{array}$ & $\begin{array}{l}- \\
-\end{array}$ & $\begin{array}{c}0.5917^{*} \\
(0.0406)\end{array}$ \\
\hline Political Globalization at time $t$ & $\begin{array}{l}-0.7755 \\
(0.3949)\end{array}$ & $\begin{array}{r}1.3736 \\
(0.8439)\end{array}$ & $\begin{array}{r}0.0654 \\
(0.0350)\end{array}$ & $\begin{array}{l}-0.2322 \\
(0.2414)\end{array}$ \\
\hline Lag-1 Political Globalization & $\begin{array}{r}0.9138 \\
(0.9563)\end{array}$ & $\begin{array}{l}-0.9237 \\
(0.4952)\end{array}$ & $\begin{array}{r}-0.0770^{*} \\
(0.0250)\end{array}$ & $\begin{array}{r}-0.5621^{*} \\
(0.1010)\end{array}$ \\
\hline $\operatorname{AB} \operatorname{AR}(1)$ & $\begin{array}{c}-2.2600 \\
{[0.0240]}\end{array}$ & $\begin{array}{c}-2.4200 \\
{[0.0155]}\end{array}$ & $\begin{array}{c}-2.4200 \\
{[0.0157]}\end{array}$ & $\begin{array}{r}-1.8400 \\
{[0.0652]}\end{array}$ \\
\hline $\mathrm{AB} \operatorname{AR}(2)$ & $\begin{array}{r}1.1100 \\
{[0.2659]}\end{array}$ & $\begin{array}{r}0.0100 \\
{[0.9892]}\end{array}$ & $\begin{array}{r}1.2200 \\
{[0.2213]}\end{array}$ & - \\
\hline
\end{tabular}

\footnotetext{
Notes: (1) Table is set for the results from the model according to the equation (6.1), applying Arellano-Bond methods
for cross-sectional time series make the estimation for the causality of diffusion of the Internet, here, Data_Length, RTT, HopDistance, TTL, on the political globalization. The first column contains the independent variables we examined. InHopDistance, TIL, on the political globalization. The first colunn contains the independent variables we examined. Intercepts are suppressed. All the entries are the values of estimators correspond to the independent variable in each row. Results here for comparison are GMM estimates. (2) Arellano-Bond test that average autocovariance in residuals of order 1 is almost 0 not failed in $5 \%$ level for all alternative specifications. Arellano-Bond test that average autocovariance in residuals of order 2 is almost 0 failed in $5 \%$ level for all alternative specifications. "*" represents the $5 \%$ significance. The paraphrased figures are the simple standard deviations, and the bracketed ones are the p-values.
}

paper effectively suggest a new way for measuring the diffusion of the Internet, which also traces the social interactions between multinational continents.

Based on our results, dynamic panel causality and sensitivity analysis demonstrate further empirically that the causality of the Internet diffusion on the different indexes of globalization and all sub-category measures for globalization in (6.1). Arellano-Bond test that average autocovariance in residuals of order 1 is 0 didn't fail in $5 \%$ level for almost all columns, so putting the one-period-lagged Internet measurement series into the explainary sets has not been statistically approved. The probability of not rejecting the hypothesis of average autocovariance in residuals of order 2 is 0 is very high, which is explicitly showing that the higher-order residuals yield no autocorrelation. In Table 16, it should be noticed that the $X_{i, t}$, the current trend of globalization, not the lagged values, has strong relationship with the current Internet diffusion, which support the impact from the Internet diffusion on the global integration, not the inverse way. we may ar- 
gue here again that how this unique new datasets of the Internet measurements can improve the calculation for social globalization, using this new Internet measurements to be the alternatives for the key contents for the Internet diffusion in multi-country environments.

\section{Conclusion}

With the measurement of the Internet cross-traffic traveling distance, we evaluate the effects of Internet distance on global industry using global indexes along with economic and financial globalization, political globalization and social globalization, associated with multiple inputs, such as the international trades and funds flows, the financial institutions and economic performances nowadays. Under the development of Internet, network construction and information technology, the evaluation of international trades and funds, financial institutions and government policies gets new sight. The major findings are that there exists significant and positive relationship between the Internet distance and globalization indexes. Aggregate cross-sectional time series data shows consistent evidence to support for the dependence between the globalization and oneperiod- lagged Internet diffusion. The impact of the Internet diffusion on globalization is supported in the empirical results by using this unique data set. We can find that the current changes in the diffusion of the Internet have no statistically significant relationship to the current globalization index, which support the impact from the Internet diffusion on the global integration, not the inverse way. Comparing cross-country institutions transformation based on the influence from the Internet service, we find persistence in the political globalization when there is free flow of information. The physical distance play less effective roles nowadays in markets. There exists significant effect from institutions to the global financial system, such as coalition between countries, and country-to-country treatment for funds transfer. 
Dynamic panel causality and sensitivity analysis demonstrate further empirically the causality of Internet diffusion on the different indexes of globalization and all sub-category measures for globalization. The causality issue points to future research opportunities, such as how this unique new data set of the Internet measurement can improve the calculation for social globalization, since the Internet diffusion across-country had been used as key content. On the other hand, as long as we know the direction of causality between the diffusion of the Internet and the degree of globalization, this unique datasets are efficient alternatives for estimating the relationship between the globalization and the diffusion of the Internet. Dynamic panel causality and sensitivity analysis further confirm the significant strong relationship between globalization and the diffusion of the Internet. The Skitter research supplies a new and efficient way with insight into the complexity of a large, heterogeneous, and dynamic worldwide topology on the diffusion of the Internet, and therefore the degree of globalization.

\section{References}

[1] Abramson, B. D. (2000), "Current Statistics: Internet Globalization Indicators", telecommunications Policy, Vol. 24, 69-74.

[2] Anderson, J. (1979), "A Theoretical Foundation for the Gravity Equation," American Economic Review, American Economic Association, vol. 69(1), pages 106-16, March.

[3] Anderson, J. And Wincoop, E. (2003), "Gravity with Gravitas: A Solution to the Border Puzzie", American Economic Review, 93:1, 170-192.

[4] Andres, L., Cuberes, D., Diouf, M. A., And Serebrisky, T. (2010), "The Diffusion of the Internet: A Cross-country Analysis", Telecommunications Policy, volume 34, issue 5-6, pp. 323-40, June-July.

[5] Antonelli And Honeyman (2000), "Wiretapping the Internet", SPIE's Symposium on Enabling Technologies. 
[6] Choi, Changkyu (2010), "The Effect of the Internet on Service Trade", Economics Letters, November, v. 109, issue 2, pp. 102-04 November.

[7] Clarke, G. R. and Wallsten, S.J. (2006), "Has The Internet Increased Trade? Developed And Developing Country Evidence", Economic Inquiry, 44(3), July, 465-484.

[8] Dreher, A. (2003), "Does globalization Affect Growth?", working paper, January.

[9] Dreher, A., Gaston, N., And Martens, P., (2008), Measuring Globalization, Springer, June.

[10] Fahy, Colleen A. (2006), "Internet versus Traditional Retailing: An Address Model Approach", Journal of Economics and Business, May-June, v. 58, issue 3, pp. 240-55.

[11] Firoiu, Boudec, Towsley, and Zhang (2002), "Theories and Models for Internet Quality of Service", Proceedings of the IEEE, May.

[12] Freund, Caroline L., And Weinhold, Diana (2000), "On the effect of the Internet on international trade", Board of Governors of the Federal Reserve System (U.S.), International Finance Discussion Papers: 693.

[13] Freund, C. And Weinhold, D. (2004), "An Empirical Investigation of the Internet and International Trade: The Case of Bolivia", working paper, Dec. 2004.

[14] Freund, Caroline L.; Weinhold, Diana (2004), "The Effect of the Internet on International Trade", Journal of International Economics, January, v. 62 , issue 1 , pp. 171-89.

[15] Freund, Caroline L., and Weinhold, Diana (2011), "The Effect of the Internet on International Trade", Trade Costs and Facilitation: Open Trade and Economic Development. Volume 2, pp. 5-23 Critical Perspectives on the Global Trading System and the WTO, vol. 18. Cheltenham, U.K. and Northampton, Mass.: Elgar 2011

[16] Goldfarb, A. And Blum, B. S. (2006), "Does the Internet Defy the Law of Gravity?", Journal of International Economics, Vol. 70 (2), December, 384-405. 
[17] Greenstein, Shane And McDevitt, Ryan (2012), "Measuring the Broadband Bonus in Thirty OECD Countries", OECD Digital Economy Papers 197.

[18] Downes, Tom and Greenstein, Shane (2007), "Understanding why universal service obligations may be unnecessary: The private development of local Internet access markets", Journal of Urban Economics. 62(1): 2-26.

[19] Greenstein, S., And Prince, J. (2006), "The Diffusion of the Internet and the geography of the Digital Divide in the United States", NBER working paper series, April.

[20] Greenstein, S. And Mazzeo, M. (2006), "The Role of Differentiation Strategy in Local Telecommunication Entry and Market Evolution: 19992002", Journal of Industrial Economics. 54(3): 323-350.

[21] Hofstader (2004), "Internet Accessibility: Beyond Disability", webtechnologies, Sep.

[22] Hill, Model (2014), "The Internet, Its Governance, and the Multistakeholder", Richard Proper Internet Governance, Geneva Info, v. 16, issue 2, pp. 16-46.

[23] Lee, Jaehwa (2012), "Network Effects on International Trade", Economics Letters, August, v. 116, issue 2, pp. 199-201 August.

[24] Gao, Maija; Hyytinen, Ari; Toivanen, Otto (2014), "Problems in Launching the Mobile Internet: Evidence from a Pricing Experiment", Journal of Economics and Management Strategy, Fall, v. 23, issue 3, pp. 483-506 Fall.

[25] Matros, R., Streitberger, W., Koenig, S., and Eymann, T. (2010), "Facing Price Risks in Internet-of-Services Markets", Economic Models and Algorithms for Distributed Systems, pp. 257-69 Autonomic Systems series. Basel and Boston: Birkhauser.

[26] Portes, R., And Rey, H. (2005), "The determinants of cross-border equity flows", Journal of International Economics 65: 269296.

[27] Pozzi, Andrea (2013), "The effect of Internet distribution on brick-andmortar sales", RAND Journal of Economics, Vol. 44, No. 3, Fall, pp. 569583. 
[28] Sharon, Loane, McNaughton, Rod B. and Bell, Jim (2009), "The Internationalization of Internet-Enabled Entrepreneurial Firms: Evidence from Europe and North America", working paper, April.

[29] Terzidis, Konstantinos, Papadopoulou, Eva, and Kosmidis, KosMAS (2013), "Customer E-Loyalty to Internet Banking: An Empirical Analysis", Global Business and Economics Review, v. 15, issue 2-3, pp. 148-62.

[30] Timmis, Jonathan (2012), "the Internet and International Trade in Goods", University of Nottingham, School of Economics, Discussion Papers.

[31] Wagner, C. S., And Leydesdorff, L. (2006), "Measuring the Globalization of Knowledge Networks", working paper, Sep..

[32] Ward (1996), "The Effect of the Internet on Political Institutions", Oxford Journals, Volume 5, Number 4 ,Page. 1127-1141. 